\title{
HOSPITALES URBANOS EN LA RIOJA EN LOS SIGLOS XVI Y XVII. ESTRUCTURAS ADMINISTRATIVAS Y FINANCIACIÓN
}

\author{
Alfredo Martínez Díez \\ Doctor, Universidad de La Rioja \\ Alf.md83@gmail.com
}

\begin{abstract}
RESUMEN: A raíz de la inclusión de elementos seculares en las estructuras administrativas de las instituciones de beneficencia y los primeros pasos en la unificación y racionalización de los establecimientos asistenciales por mandato real a finales del siglo XV, se produce un punto de inflexión en la evolución del sistema hospitalario a nivel nacional que en el caso de La Rioja supone una rápida municipalización de la asistencia hospitalaria centrada en los núcleos urbanos gracias a la existencia previa de un elevado número de hospitales en relación al Camino de Santiago y las características político-económicas de la región.
\end{abstract}

Palabras clave: Hospital, cofradía, beneficencia, urbanismo.

\section{URBAN HOSPITALS IN LA RIOJA IN THE XVI AND XVII CENTURIES. ADMINISTRATIVE ORGANIZATION AND FUNDING}

\begin{abstract}
Following the inclusion of secular elements in the administrative structures of charitable institutions and the first steps in the unification and rationalization of assistance facilities by a royal mandate in the late fifteenth century, a turning point in the evolution of the hospice system on a national level, which in the case of La Rioja implies a fast municipalization of hospital assitance centered on urban settlements, thanks to the previous existence of a large number of hospitals as a consequence of the Camino de Santiago and the political and economic traits of the region.
\end{abstract}

Keywords: Hospital, brotherhood, beneficence, urban planning.

Recibido: 3 de Octubre de 2017 Aceptado: 12 de Diciembre 2017 
El sistema hospitalario moderno surge en torno a centros monásticos como parte de su efecto en el urbanismo medieval, estructurándose la actividad local en torno a la división entre seglar, sanctus, sanctum, sanctissimus que se observa en zonas de gran actividad religiosa en Europa, como Irlanda o el Sur de Francia. En el caso de La Rioja con gran influencia del Camino de Santiago no únicamente como vía de peregrinos ${ }^{1}$ sino determinante en el proceso urbanístico en torno a instituciones religiosas como Santo Domingo de La Calzada y vados naturales del Río Ebro como Logroño. El Camino se convierte en una importante vía comercial, creando un interés en las elites económicas por su mantenimiento y desarrollo, de modo que las localidades con más recursos con los que asistir a los peregrinos comienzan a concentrar los servicios asistenciales provocando la aparición o desarrollo de establecimientos que inicialmente no dependen del municipio, dirigidos por religiosos. Se centran en el hospedaje, auxilio y atención sanitaria de peregrinos y pobres, de acuerdo con las obligaciones dictadas por la doctrina cristiana, junto con la simple necesidad provocada por el gran número de necesitados; y el riesgo que el propio Camino de Santiago supone como vector de entrada de enfermedades, agravado por las protecciones y privilegios legales del peregrinaje ${ }^{2}$. Incluso a principios del siglo XVIII siguen promoviéndose filosófica e institucionalmente el peregrinaje y la hospitalidad como una virtud de modo que los que asisten a los peregrinos obtienen méritos espirituales semejantes a los que peregrinan ${ }^{3}$.

\section{El sistema hospitalario en La Rioja}

A finales del siglo XV comienza una reforma de estas instituciones en relación a la incipiente centralización del poder, unificándose los pequeños hospitales de cada localidad en idealmente un establecimiento por decreto de los Reyes Católicos y apoyado por bulas papales confirmando su establecimiento, como en Logroño en $1515^{4}$. Sin abandonar su relación con el peregrinaje, la asistencia se centrará en los pobres locales, que componen un importante porcentaje de la población urbana, mostrando interés por la identificación y clasificación

1. Existen un gran número de obras en torno al peregrinaje jacobeo en La Rioja, véase, LARRAURI REDONDO, Sergio, LOSANTOS BLANCO, Silvia, Los hospitales del Camino Francés en La Rioja, Logroño, 2010; DE LA IGLESIA DUARTE, J.I. (coord.), IV Semana de Estudios Medievales, Nájera, 2 al 6 de agosto de 1993, Logroño, 1994.

2. LÁZARO RUIZ, Mercedes, "La lepra en el Camino Francés a su paso por La Rioja", en DE LA IGLESIA DUARTE, J.I. (coord.), IV Semana..., pp. 323-340.

3. "Ved aora quan grande merito tendrá quien de remotas Tierras peregrina, por visitar los santuarios [...] Y conocereis quanto ganan [...] los que caritativos les ofrecen sus casas, su asistencia [...] á tan poca costa [...] consigue los meritos que les logran tantos trabajos á los que peregrinan"; GONZÁLEZ DE TEJADA, José, Historia de Santo Domingo de La Calzada, Abrahan de La Rioja, Madrid, 1702, p. 101.

4. AMLo, IGE, 467, Bula de León X. 
de los "verdaderos pobres" merecedores de la atención para reducir su impacto económico e involucrando a la administración municipal y la élite local tanto por convicción religiosa o deseo de notoriedad como por el peligro de conflictividad social ${ }^{5}$. A pesar de esta medida el sistema económico riojano, de carácter autárquico y fundamentalmente agrario favorecerá a los grandes propietarios que centran su atención en los mayores beneficios del viñedo y la lana, llevando a los labradores a subsistir arrendando tierras o trabajando de jornaleros lo cual en tiempos de sequía y hambrunas provocaría migraciones hacia las ciudades ante las cuales las administraciones tomarían diferentes medidas en función de las circunstancias inmediatas como restricción del movimiento de los jornaleros en poblaciones vinícolas que dependían de su labor o periódicas redadas y expulsión de vagabundos de los núcleos urbanos, careciendo de un proyecto constructivo a nivel regional.

De modo que pese a su origen fundamentalmente religioso los hospitales serán integrados en el tejido administrativo municipal con diversos grados de implicación que reflejan las características preexistentes como en localidades donde los cabildos eclesiásticos forman parte de la administración. Pueden dividirse los hospitales entre los religiosos ${ }^{6}$, los dependientes de patronazgos privados, o los municipales; aunque a un nivel práctico las instituciones funcionaron normalmente con un modelo mixto. Independientemente de esta diferenciación pero apoyándose en estos actores para su administración se encuentran los establecimientos de Patronato Real como las leproserías, que al contar con apoyo y control real también serían afectados por los impulsos de renovación a principios del siglo $\mathrm{XVI}^{7}$. La Rioja contó durante la Edad Moderna con al menos 39 establecimientos dedicados al tratamiento de leprosos según refiere Lázaro Ruiz, pertenecientes a San Antón (3 hospitales y 12 ermitas), la

5. Véase ABREU, Laurinda (ed.), Asistencia y Caridad como estrategias de Intervención Social: Iglesia, Estado y Comunidad (s. XV-XX), Zarautz, 2007; DE LA IGLESIA, Jesús, "El debate sobre el tratamiento a los pobres durante el siglo XVI", en CAMPOS Y FERNÁNDEZ DE SEVILLA, Francisco Javier (coord.), La Iglesia española y las instituciones de caridad, Madrid, 2006, pp. 5-30.

6. CATALÁN MARTÍNEZ, Elena, "Parroquias y curas en el obispado de Calahorra y La Calzada (siglos XI a XVI)", en Obradoiro de Historia Moderna, 22, Santiago de Compostela, 2013 , pp. $35-62$, en contraste con el $37^{\prime} 85 \%$ total, un $60-80 \%$ de las parroquias riojanas dependen de la diócesis, sin incluir las instituciones que dependen de las Órdenes Hospitalarias que a menudo cuentan con el patronazgo de grandes casas nobiliarias permitiendo una cierta independencia del obispado, como es el caso del hospital de Navarrete dependiente de la Orden de San Juan de Acre, relacionado con los Manrique de Lara.

7. Se regula que en estas casas "pobres y enfermos fueran bien tratados y mantenidos", Novísima Recopilación, L. VII, T. XXXVIII, L. I.: Carlos I y Da Juana (1528). NR, L. VII, Tít. XXXVIII, L. II, Reyes Católicos (1477), pp. 694-695, en las Leyes III (1565) y XXV (1785) se confirma el aislamiento en las leproserías, la cuarentena sería el método empleado contra afecciones semejantes, también se establece que médicos y cirujanos se convierten en la máxima autoridad en cuestiones médicas. 
Magdalena (16 ermitas), y San Lázaro (8 hospitales). Funcionalmente dependían de los regidores y justicias de los concejos o en ocasiones de los cabildos eclesiásticos, con excepción de las ermitas y oratorios que no se hallaban cercanas a núcleos urbanos ${ }^{8}$.

Los hospitales diocesanos no son ajenos a las actuaciones reales, la sede episcopal es responsable del control de la actividad de los establecimientos con función benéfica en su jurisdicción ${ }^{9}$, y los esfuerzos de renovación de la Hacienda Real del siglo XV se reflejan ya a mediados del XVI, a través de Averiguaciones y visitas diocesanas a los establecimientos de la diócesis ${ }^{10}$. A través de estos documentos resultan 27 hospitales diocesanos en La Rioja ${ }^{11}$, a los que habría que añadir aquellos que no dependían de la diócesis por completo, como es el caso del Hospital de Santo Domingo, el de Calahorra (en conjunción con cofradías), o los de Navarrete, Haro y Logroño.

Los visitadores diocesanos serán los encargados bajo la autoridad del obispo de revisar las instalaciones y los libros de cuentas, demandando la realización de ajustes, informes o periódicos apeos de las propiedades, comprobando que se cumplen los estándares señalados y apremiando a realizar los cambios necesarios. Los propios libros de las instituciones asistenciales que se han conservado se elaboran en ocasiones por razón de las visitas diocesanas por la orden episcopal de mantener unidos los cuadernillos que empleaban los administradores anteriormente para facilitar el control y la revisión de las finanzas ${ }^{12}$. Las visitas se efectúan anualmente

8. IBÁÑEZ RODRÍGUEZ, Santiago, "Hospitales del Camino de Santiago en la Diócesis de Calahorra y La Calzada", en DE LA IGLESIA DUARTE, J.I. (coord.), IV Semana..., pp. 309-321, p. 318, refiere los lazaretos más importantes, Logroño, Nájera y Santo Domingo, Montalbo, Haro y Sajazarra. El lazareto de Logroño se mantenía bajo Patronato Real para evitar interferencias y abusos. En 1487 es necesario que la Chancillería emplace un requerimiento contra el concejo de Logroño, que había tomado control del hospital en contra del nombramiento de Nicolás de Puentedura como provisor por la Orden de San Lázaro (AGS, RGS, LEG, 148708, 209), seguida de la petición de la ciudad por razón de asegurar el patronato real (AGS, RGS, LEG, 148903, 401, Medina del Campo, 1489), aunque finalmente se reconocería la justicia de los títulos de posesión de la casa por Puentedura (AGS, LEG, 148907, 218 y 219).

9. AHPLR, Beneficencia, 35, ff. 100v-102r, en la visita al hospital de Navarrete del Dr. Barrera se establece: "para bien y buen gobierno del dicho ospital y de sus rentas mando y ordeno [...] que de todas las pagas que hizieren cobrar, carta de pago como sea la cantidad de seis Reales arriba [...] que no las mostrando no se las pagaran [...] aunque las ayan exibido a la Junta de Regimiento".

10. ACC, 324, y AHDLo, 279.

11. LARRAURI REDONDO, S., LOSANTOS BLANCO, S., Los hospitales..., sobre los 52 totales para la Diócesis en, IBÁÑEZ RODRíGUEZ, S., "Hospitales del Camino..., p. 313, no señala los de Navarrete, Logroño y Santo Domingo, dudando de la existencia de actividad o fondos en los dos primeros.

12. AHPLR, Beneficencia, 35, ff. 73v-75r; En la visita de 1608 del Licenciado Orive al Hospital de Navarrete se observa que los documentos "no estaban en estado de poder tomar asento lo qual mando al susodicho la ponga en mexor forma que se pueda y reducida en la 
aunque no siempre son mencionadas por la ausencia de incidentes, quedando registradas en los libros propios del obispado, hallándose a menudo ligadas a los cambios del administrador de la institución. Esta práctica se mantiene durante toda la Edad Moderna, especialmente tras la consolidación del poder diocesano por el Concilio de Trento y no se limita a los establecimientos dependientes de la diócesis. A mediados del siglo XVI se efectúan visitas por todos los arciprestazgos, en parte motivadas por asegurar el control del obispo sobre los territorios bajo su tutela, en una época en la que los conflictos con los diferentes poderes regionales, tanto de la nobleza como los propios religiosos, se recrudecen por la pugna sobre el control de las rentas y beneficios ${ }^{13}$, el simple hecho de hacer necesaria la presentación de libros ante tantas autoridades será uno de los factores determinantes en la escasez en documentos propios de los diferentes establecimientos por dispersión y pérdida, a pesar de los intentos de las administraciones de recuperarlos.

El intervencionismo eclesiástico no se limita al obispado, abundan los conflictos internos entre diferentes parroquias, el cabildo de La Redonda se resistirá a perder el control sobre las cuentas de los hospitales que anteriormente estaban a su cargo que ahora quedan nominalmente bajo control de las cofradías y los concejos Ilegando a reclamar al Consejo Real ${ }^{14}$, lo que determina que las instituciones afectadas deben someter sus cuentas a una auditoria por una tercera parte. En Nájera el Cabildo de la Iglesia de la Cruz intentará liberarse del control de Santa María de la Real y a mediados del siglo XVI obtendría una bula que les permitía poseer una capellanía propia independiente de la administración de la Abadía ${ }^{15}$.

manera que mas conbenga", también disponen que dado que el hospital "tiene muchos censos menudos y pequeños dio liçencia a dicho Juan de Corral para que los pueda reducir [...] de manera que se perpetuen [..] y que sean mejores".

13. Para los conflictos y características políticas y jurisdiccionales en la Diócesis de Calahorra-La Calzada véase, IBÁÑEZ RODRÍGUEZ, S., "La Diócesis de Calahorra a mediados del siglo XVI según el libro Libro de visita del Licenciado Martín Gil", en Brocar, 21, Logroño, 1998, pp. 135-183.

14. AGS, RGS, LEG, 149803, 244, 31/03/1498, Alcalá de Henares.

15. Se suceden una serie de conflictos como la sustracción del Sacramento y otros ornamentos litúrgicos, para la capilla del Hospital de la Madre de Dios con la consecuente denuncia del Monasterio (ARChV, PL Civiles, Pérez Alonso (F), 1316/6 y 1318/1, 1555-1562, escribanía de Alonso de Santiesteban) que retiene las bulas hasta una Ejecutoria en 1562 (ARChV, Registro de Ejecutorias, 1030/42) que ordena su devolución y el cese de las interferencias para que la Iglesia de la Cruz se establezca como parroquia con la consecuente independencia del hospital, aunque continuarán colaborando al estar su capellanía adscrita al Hospital de la Abadía, en el siglo XVII se registra en el libro de cuentas un censo anual: "Cavildo de la Cruz - Yten Parece por el libro quarto de censos y ratificaciones [...] que la fabrica y la yglesia y capilla real de la cruz desta ciudad otorgo censo perpetuo en favor de la dicha abadia y ospital de tres ducados de censo perpetuo en cada un año" (AHPLR, DP, 225/1, f. 30r). 
Si bien no puede hablarse de una red hospitalaria las características regionales, especialmente en la Rioja Alta en relación con el Camino de Santiago y diversos centros de culto de gran importancia desde la Edad Media como San Millán de la Cogolla, determinará la existencia de multitud de establecimientos asistenciales, principalmente en la forma de hospicios y albergues dedicados a los peregrinos pero también a los necesitados, que añadirán las funciones de centro sanitario a su actividad habitual, centrada de nuevo en estos colectivos dado que el carácter de la práctica médica hace innecesario el disponer de espacios acondicionados más allá de su uso como centros de cuarentena ante epidemias. La previa existencia de estos establecimientos de temprana fundación dependientes de una colección heterogénea de instituciones no relacionadas entre sí a través de la administración se convertirá en uno de los factores que llevarán al estancamiento de la evolución de la asistencia hospitalaria en La Rioja. Al igual que en cualquier región carente del dinamismo de las grandes urbes o los núcleos comerciales costeros el modelo hospitalario no presentará grandes cambios hasta que comiencen a observarse los efectos de las tesis ilustradas y las renovaciones liberales en el siglo XIX. Hasta la formación de una base poblacional capaz de ejercer presión institucional y política el control de los cambios a nivel filosófico, legal y administrativo permanecerá bajo el control de la nobleza y la Iglesia como actores y promotores del cambio social ya fuera por actuación propia o a través de su influecia y relaciones de clientelismo con los funcionarios administrativos ${ }^{16}$. El modelo responderá a una combinación del hospicio humanista de Vives con el de Pérez de Herrera, exceptuando la distinción que éste último hace entre el Hospital como hospicio y el Hospital General como centro sanitario, tanto por falta de medios como de intenciones.

Las poblaciones de mayor tamaño cuentan con la ventaja de disponer de diferentes hospitales ya establecidos anteriormente, generalmente a partir de la donación u Obra Pía establecida por el fundador y dependientes de un cabildo eclesiástico y una cofradía, como es el caso de Santo Domingo ${ }^{17}$, con gran heterogeneidad en cuanto a sus instalaciones, que en gran número de casos carecen de edificios exclusivos, usando estancias en un edificio preexistente o casas de tamaño similar a las familiares como se da en la mayoría de los "hospitales" rurales. Los grandes hospitales de La Rioja se encuentran ligados a los mismos factores que determinan el desarrollo urbano regional por lo que no es de extrañar que con escasas excepciones los encontremos en las mayores villas, destacando los hospitales de Logroño, Nájera y Santo Domingo.

16. GÓMEZ URDÁÑEZ, J.L., LORENZO CADARSO, P.L., "Las comunidades rurales frente al estado absoluto", en Mélanges de la Casa de Velázquez, T. 29-2, Madrid, 1993, pp. 79-92.

17. SÁINZ RIPA, Eliseo, "La atención a los hombres del camino en La Rioja", en DE LA IGLESIA DUARTE, J.I. (coord.), IV Semana..., p. 142, desde 1137. 
Puede observarse que Logroño ya se postulaba en el siglo XV como un futuro punto de referencia para la articulación político-administrativa riojana ${ }^{18}$ gracias a su paso del Ebro, moderado intervencionismo nobiliario y relativa independencia del control de la diócesis. Contaba con la presencia de un gran número de órdenes religiosas que establecieron pequeños hospitales, lo cual convierte en un buen ejemplo de los nuevos hospitales producto de las políticas de agregación iniciadas por los Reyes Católicos al Santo Hospital de María de Rocamador y Santiago ${ }^{19}$ de la Ciudad de Logroño, Ilamado también de forma indistinta de la Misericordia o General, situado entre el Convento de San Francisco y la Plaza del Coso. Aparece a comienzos del siglo XVI con sanción papal ${ }^{20}$, aunque la construcción ya se había iniciado a finales del siglo XV a juzgar por la petición en 1489 a la Real Chancillería para poder continuarla ${ }^{21}$. Su creación forma parte del esfuerzo de unificar y coordinar los diferentes establecimientos presentes en la ciudad, principalmente los hospitales de Roque Amador y la Misericordia, junto con los de Santiago, la Costanilla, la Villanueva y San Blas ${ }^{22}$.

El patronazgo se compartía por disposición del mayorazgo que se estableció para su creación, entre la administración municipal a través del Procurador y una serie de representantes de las cofradías de los hospitales absorbidos, con especial relevancia de la Cofradía de Santiago ${ }^{23}$. Se trata de un edificio de nueva construcción que aúna la asistencia benéfica y sanitaria, función vista con recelo debido al riesgo de contagios $^{24}$, provocando que el terreno para su edificación se situara extramuros a mediados del siglo XVI. Contaba con dos plantas siendo la de abajo la "de los pobres" alojados en las "quadras". No puede afirmarse cuantas personas podían alojarse a un mismo tiempo, aunque a mediados del siglo XVII se realizan obras para la creación de 14 "alcobas" en las dos cuadras para los convalecientes ${ }^{25}$,

18. ÁlVAREZ CLAVIJO, Ma Teresa, Logroño en el siglo XVI: Arquitectura y Urbanismo, Logroño, 2003.

19. Por la Virgen de Róc Amador (sur de Francia) relacionada con san Amador y la ruta jacobea. También "de Roque Amador", por un hospital preexistente, canonizado en 1584 como uno de los patrones de los peregrinos y considerado milagroso ya a finales del siglo XV como protector ante la peste.

20. AMLO, 12/15, en LARRAURI REDONDO, S., LOSANTOS BLANCO, S., Los hospitales..., p. 97.

21. AGS, RGS, LEG, 148903, 85, Medina del Campo, 08/03/1489.

22. Estos nombres seguirán apareciendo en la documentación ocasionalmente debido a su existencia a un nivel institucional teórico por las Obras Pías ligadas a los mismos.

23. AHPLR, PN 472, Cristóbal Rodríguez, 01/06/1532.

24. AGS, RGS, LEG, 148903, 85, ya en 1489 se planteaba su construcción, en 1492 se propondría su situación cerca del convento de Valcuerna (AGS, RGS, LEG, 149202, 85) con oposición de los dominicos. LARRAURI REDONDO, S., LOSANTOS BLANCO, S., Los hospitales..., p. 130; se refieren las observaciones del Lic. Guevara, sobre la insalubridad y la humedad del anterior emplazamiento.

25. AMLo, LAM, 1657, sesión de 19 de Junio, se presentan las cuentas del Hospital de Rocamador. 
se refieren en el inventario de 1559 más de 22 colchones en varias estancias, si bien algunas pueden tratarse de almacenes ${ }^{26}$. Este hospital presentará el mayor grado de evolución entre los hospitales riojanos, convirtiéndose finalmente en el Hospital Provincial. El edificio original sobrevive hasta mediados del XIX, y en 1871 Amadeo I inaugurará el nuevo hospital, situado cerca del antiguo Hospital de Rocamador que sería empleado como cárcel de forma temporal.

En villas como Navarrete también se forma un nuevo hospital (San Salvador) con licencia del Duque de Nájera, a raiz de los problemas jurisdiccionales con respecto al preexistente Hospital de San Juan de Acre entre la diócesis y el comendador de la Orden, que en 1581 es el propio Juan Manrique de Lara, una extensión del conflicto entre las autoridades eclesiásticas riojanas y los Duques de Nájera por los derechos de visitación y administración económica, acudiendo los segundos al papado para confirmar su independencia ${ }^{27}$, del mismo modo hubo problemas entre Fuenmayor, Entrena y Medrano sobre la administración del Hospital de San Juan ${ }^{28}$.

En el caso de Nájera destaca por su importancia el Hospital de la Abadía, anteriormente Ilamado Alberguería de Santa María la Real, fundado por concesión de García III de Nájera y su mujer Estefanía de Foix en el siglo XI. Posteriores reyes ratificaron el patronazgo del hospital, actuando el abad como administrador, aunque entre el siglo XIV y XV la propiedad es cedida y parece desvincularse de la Abadía a cambio de un pago anual ${ }^{29}$. Pese al Patronato Real se le permitirá la resistencia ante la evolución del sistema hospitalario, en especial su mantenimiento del Hospital de Mujeres por motivo de las Obras Pías, mientras que el resto de pacientes dependen de las cuadras de un edificio que ya en el siglo XVII está ruinoso, la sección de mujeres mantiene camas y cocina propia, mientras que los demás necesitados acudirían al hospital en busca de limosna y atención para ser despachados rápidamente.

Y como institución representante del control diocesano, documentándose su funcionamiento desde 1137, el Hospital de Peregrinos de Santo Domingo se fundó bajo la dirección del Abad de la Iglesia de Santa María y su cofradía asociada $^{30}$. Debido a la importancia de la ciudad como vía de peregrinaje los obispos de Calahorra mostraron un gran interés por su control, e incluso la Corona y el papado trataron de favorecer a la futura catedral. A finales del siglo XIV o principios del siglo XV se construyó un nuevo edificio para el Hospital, con una planta baja destinada a los hombres, la capilla y la

26. AHPLR, DP 223/1.

27. LARRAURI REDONDO, S., LOSANTOS BLANCO, S., Los hospitales..., p. 159.

28. ARChV, REGISTRO DE EJECUTORIAS, 1716, 20, 16/05/1592.

29. CANTERA MONTENEGRO, Enrique, "La alberguería de Santa María de Nájera", en Anuario de Estudios Medievales, n 13, Barcelona, 1983, pp. 367-380.

30. ACSD, Leg. 22-5, perg. 419 por 85, citado en SÁENZ TERREROS, $M^{a} V^{a}$, El hospital de peregrinos y la cofradía de Santo Domingo de La Calzada, Logroño, 1986, p. 12. 
intendencia; y la primera a las mujeres, los enfermos y la administración. A mediados del siglo XVI podía llegar a atender a unas 200 personas diarias ${ }^{31}$ (peregrinos fundamentalmente), convirtiéndose en uno de los hospitales con mayor volumen de atendidos de la diócesis y el mayor de La Rioja. Hasta el siglo XVIII será una institución de fuerte carácter religioso centrada en los peregrinos, apoyada por un cierto proteccionismo de la Corona hacia las instituciones calceatenses, que progresivamente va siendo sustituido por el control seglar pese a la gran resistencia por parte de los diferentes obispos y el cabildo eclesiástico.

\section{La administración de los Hospitales}

La administración de los establecimientos asistenciales depende de los patronos del mismo, responsables del inmueble y las rentas, y una corporación institucional compuesta por elementos de la administración municipal o religiosa junto con las cofradías que contribuyen para su funcionamiento. Dependiendo del origen y titularidad, el administrador es un oficial local de alto rango para el caso de las grandes poblaciones, normalmente el abad o deán en el caso de las religiosas y el Justicia o los regidores para las municipales, en las de menor tamaño, el cura y las juntas vecinales.

Así puede verse por ejemplo el Hospital de la Abadía de Nájera, dirigido por personal nombrado por el abad ${ }^{32}$ (que al menos de nombre ejerce como mayordomo), el prior y los cofrades elegidos al efecto. Todos ellos elementos que forman parte del cabildo eclesiástico de la ciudad, a diferencia de los de Santo Domingo y Calahorra, dependientes directamente del obispo que nombra usualmente al deán u oficial religioso correspondiente hasta la adición de cofrades seglares que se unen en lo referente a estas instituciones al cabildo eclesiástico a pesar de que su presencia a nivel administrativo es principalmente nominal, dado que se continúa recurriendo a personal ordenado.

En hospitales municipales que no se adscriben a un solo cabildo como los hospitales de Logroño, Calahorra o Haro los patronos, forman una junta administrativa que incluye al cabildo municipal y el eclesiástico para la toma de decisiones referentes a la gestión del hospital, aunque desde sus inicios

31. LÓPEZ DE SILANES, Ciriaco, SÁINZ RIPA, E., Colección Diplomática Calceatense. Archivo de la Catedral (1451-1499) y Archivo del Hospital (1431-1497), Logroño, 1992, p. 29.

32. Es el rey quien nombra al administrador, en 1622 es nombrado administrador Francisco Andrés de la Torre por "tres años mas o menos", por orden de Felipe IV encargando tanto al abad como al municipio "el beneficio y acrecentamiento de los bienes y rentas del dicho mi ospital real y recoxereis y tratareis bien a los pobres emfermos que a el fueren reciviendolos con todo amor y piedad de manera que sea echa la caridad, abrigo y recoximiento que combiene y se deve a los pobres" (AHPLR DP 225/1, ff. 2v-3r). 
el corregimiento tiene preferencia sobre las cofradías y las parroquias ${ }^{33}$, en términos generales La Rioja presenta una mayor implicación de los elementos municipales en todas las instituciones asistenciales ${ }^{34}$.

Los hospitales parroquiales o de menor tamaño no se ajustan necesariamente a este esquema, muchos de ellos fueron formados por iniciativa de las cofradías o parroquias y a partir de Obras Pías manteniéndose con un cierto grado de independencia desde sus orígenes como albergues u hospicios. Progresivamente serán involucrados en el sistema hospitalario racionalizado y promovido por la Corona y en su mayor parte serán absorbidos por otros establecimientos mayores aunque algunos de ellos sobrevivirán hasta sustituir a hospitales de mayor relevancia por apoyo institucional como parte de conflictos entre los diferentes grupos de poder locales o por el abandono o renuncia en adoptar el papel de hospital propiamente dicho, como ocurrirá con el Hospital del Refugio en Nájera con respecto al Hospital de la Abadía que comenzará a recibir el apoyo de familias locales. Tras su creación se registra un Juro de 14.000 maravedíes procedente de disposiciones testamentarias de varios vecinos ${ }^{35}$. A medida que avanza el siglo XVII pueden encontrarse más establecimientos con administración compartida, comunes en localidades que pertenecen a la jurisdicción de los grandes señoríos como el ducado de Nájera, que afecta a Fuenmayor y Navarrete entre otras.

Esta administración se apoyaría en una serie de oficiales escogidos por un período determinado por los administradores, lo cual se convierte en un mero trámite en la práctica para determinadas instituciones. Los establecimientos funcionan bajo control de un Mayordomo o Provisor, generalmente un beneficiado de la parroquia en los religiosos y un miembro de la administración en los municipales, aunque también se escoge personal seglar de las cofradías que además de salario obtiene consideraciones a nivel municipal, como exención de impuestos o servicios concejiles ${ }^{36}$. Los cargos administrativos de los hospitales se convertirán en otro puesto disputado como parte de la lucha

33. Ya en 1498 se recibe en Logroño orden recordando al corregidor que es su responsabilidad exigir la presentación de cuentas del hospital sin delegar esta responsabilidad en los cabildos de las colegiales de Albelda y La Redonda y sus cofradías (AGS, RGS, LEG, 149803, 244, Alcalá de Henares).

34. CARASA SOTO, Pedro, "Crisis y transformación de la beneficencia del Antiguo Régimen: Aproximación al sistema hospitalario de La Rioja entre 1750 y 1907", en Cuadernos de investigación: Historia, T. 10, Fasc. 1, Logroño, 1984, pp. 7-26, p. 14.

35. AGS, CME, 1421, 15.

36. No se limitaban a la administración, en un ejemplo concreto, en 1622 encontramos un auto judicial del Hospital de Peregrinos en favor de Pedro de Vitoria contra la ciudad por la resistencias de éste de entrar a servir como Mayordomo de la ciudad, afirmando la administración del hospital que "se obligo junto con su mujer de servir todos los dias de su vida en dicho Sto. Hospital" (AHPLR, Judicial, 1261/9, 1622, 1622, Santo Domingo de La Calzada, escribanía de Juan de Valencia). 
de influencias entre los estamentos dominantes, y a pesar de que la mayordomía es teóricamente escogida de forma anual, también degenerará en un título que no se asocia necesariamente al gobierno de los establecimientos, recayendo la dirección en términos prácticos en otros oficiales como los capellanes en los núcleos urbanos ${ }^{37}$.

Algunos casos como el Hospital de la Madre de Dios de Haro la institución se constituye oficialmente bajo jurisdicción compartida entre la administración municipal y la eclesiástica y aunque legalmente se acude a los oficiales del ayuntamiento ambas instituciones aportan al menos un Mayordomo ${ }^{38}$. El hospital de Calahorra, pese a ser administrado por el cabildo catedralicio, se vale asimismo de la administración municipal, en 1560 se nombra a Diego Tomás, Procurador General de la ciudad, como mayordomo del mismo, encargándole "de lo bisitar e que no aya en el bagabundos ni otra mala gente e que los enfermos se hagan bisitar de los medicos" ${ }^{\prime 39}$, muestra de la preocupación del malgasto de los recursos en los pobres no legítimos.

Dado que la administración de los hospitales suele ser compartida por diferentes individuos o forma parte de la administración pública no resulta sencillo encontrar cuentas en las que aparezcan pagos al administrador, hasta la regularización del siglo XVIII que obliga a una mayor precisión contable por encargo de los visitadores, hallándose así que el abad de Santa María la Real recibe anualmente por su cargo 660 ducados y de seis a doce fanegas de trigo, un ejemplo del abuso y la malversación que caracterizan las instituciones asistenciales de la Edad Moderna tan criticada en la obra de Vives, que observó como los administradores, en especial los eclesiásticos a los que presuponía estas obligaciones, actuaban en persecución del lujo y otros intereses terrenales aprovechándose de la caridad de los donantes. Las retribuciones de los oficiales varían en función de la capacidad económica de la institución y no debe considerarse que estos fueran todos los ingresos del individuo en particular ${ }^{40}$. En

37. La mayordomía se centra en la legitimación, en 1561 se nombra en el Hospital de Rocamador a Hernando de la Torre, con autoridad para "demandar rezebir y ver y cobrar en Juycio y fuera del de todas y quales quier personas de qual quier Estado y condicion que sean, todos los zensos, Juros y rentas debydos y pertenezientes al dicho hospital [...] por conocimientos que obligaciones, Esscripturas publicas y contratos, y testamentos, y legatos, y mandas, y donaciones, y quentas, y fenecimentos de qual quier razon que sea" (AHPLR, Judicial, 927/7, f. 55, 1550-1562, Logroño, escribanía de Pedro del Valle).

38. AM Haro, LAM, 1678, en 1682 se designa al Licenciado Diego Hurtado, beneficiado de la Iglesia Parroquial, como Mayordomo Mayor del cabildo eclesiástico, y en nombre del concejo y vecinos de Haro toma el cargo de Mayordomo Seglar el Procurador General, en ese momento Antonio de Coscojales.

39. AMC, LAM 1560, sesión de 18 de Enero.

40. En 1545 se consideraba para la Diócesis de Calahorra-La Calzada como una cifra que permitía a un sacerdote beneficiado vivir con la dignidad que se le presuponía $12.000 \mathrm{mrs}$. (CATALÁN MARTíNEZ, E., "Parroquias y..., p. 58, el 54\% reporta rentas en torno a los 2.000- 
función de los recursos del hospital se encuentran entre los 1.000 y $4.000 \mathrm{mrs}$. anuales, cantidad que puede considerarse testimonial, dado que se asemeja al salario de otros miembros del personal como los hospitaleros, capellanes y criados.

\subsection{Las Cofradías}

El proceso de municipalización de la asistencia comenzará a involucrar a la administración pública y a particulares de forma lenta pero continuada, siendo éstos últimos a través de las cofradías quienes ejercerán un mayor efecto en la evolución de las instituciones en función de la capacidad económica y relevancia de sus miembros. Por la imposibilidad o displicencia de los patronos y la Iglesia, la financiación de estos establecimientos se mostrará insuficiente para hacer frente a las necesidades del pauperismo, y se acudirá a las obligaciones religiosas o la promesa de beneficios espirituales para atraer la colaboración de los pudientes de la población, estructurando estos esfuerzos en cofradías en torno a una parroquia o santo particular.

Tradicionalmente las cofradías asociadas a la beneficencia se componían de religiosos ordenados, lo cual comienza a cambiar a finales de la Edad Media en parte como respuesta a la aparente falta de donaciones y contribuciones relacionada con las circunstancias políticas que sufre La Rioja como frontera constante entre los diferentes reinos, que lleva a una inestabilidad del apoyo particular y real a los centros religiosos en función a intereses estratégicos y políticos, provocando que las iglesias busquen nuevos ingresos con los que seguir manteniendo sus fábricas y labores, así como su estatus. Desde el siglo XV se permitirá a seglares con capacidad económica unirse a las cofradías, atraídos por beneficios religiosos como las indulgencias, y el impulso a su notoriedad como parte de las nuevas elites urbanas. Este proceso resulta especialmente evidente en las poblaciones con mayor intervencionismo de la Iglesia como es el caso de la Cofradía de la Iglesia de Santo Domingo, compuesta de religiosos hasta una nueva ordenación establecida en 1443:

Sepan quantos esta carta de hordenaçion de confradia vieren e oyeren como los señores dean y cabildo [...] movidos por buen proposito e santa entençion e porque el serviçio de Dios las obras sumptuosas que de cada dia en la dicha eglesia se labran e fazen bayan a cabo e

\footnotetext{
3.000 mrs., y sólo un 12\% supera los 6.000 (valor máximo 23.084 del arcediano de Logroño) y en grandes ciudades como Logroño en el XVII los grandes oficiales percibían en torno a los 100.000 mrs. (AMLo, LAM 1654-1659). La cifra mínima de 12.000 mrs. era raramente alcanzada, en 1579 en Calahorra se discute subir el salario de los Tenientes de la ciudad, dado que "Con los 8.000 mrs. no podian vivir" (AMC, LAM 1579, Sesión de 12 de Marzo), a principios del siglo XVII el jornal de un trabajador era de 1-3 reales.
} 
adelante e porque las obras de misericordia [...] en el dicho ospital mas largamente sean cumplidas e continuadas e porque [...] todos en el dia del iuyzio estaremos ante el tribunal de nuestro Señor Ihesu Christo de guisa e manera que cada uno de nos dara quenta de las obras de misericordia que nos encomendo. Por ende nos cobdiçiando [...] que las animas christianas de los vivos e finados se spiritual benefiçio sean mas largamente ayudadas [...] que los dichos confrades sean resçebidos [...] en todas las indulgençias [...] veynte e ocho mill e quatroçientos e cinquenta e un años de perdon mas dozientos e noventa e quatro dias [...] les den cartas de confradia ${ }^{41}$.

Una impetra del obispo Alonso de Castilla en 1523 reduciría la contribución necesaria para la pertenencia a la cofradía de los 36-100 mrs. anteriores a diez mrs. anuales "para la dicha Obra e ospital" 42 en un proceso que "democratiza la composición de los Cofrades"43, atrayendo más donaciones y testamentos. El Hospital de Logroño se beneficia de similares apoyos, Clemente X emitió bulas para beneficio de la Cofradía de la Misericordia y de la Capilla de Santa Catalina, patrona del hospital, incluyendo "Yndulgencias en fabor de las Animas del Purgatorio para que con cada Misa que se digese en el Altar de la Santa Cruz sita en la Yglesia y hospital de Santa Cathalina saliesen del Purgatorio las Almas de los Difuntos cofrades y cofradesas de dicha Cofradia por quienes se celebrasen: cuia concesion fue por 7 años" ${ }^{\prime 4}$.

Es evidente la retórica religiosa asociada a la búsqueda de salvación apelando no al beneficio social, sino al miedo al juicio divino, que requiere la adquisición de estas exenciones temporales del castigo eterno y se convertirán en el objeto de debate entre los teólogos de la época, criticadas por Lutero como una distracción de las obligaciones religiosas que no deben realizarse bajo coacción humana. La religiosidad está integrada en la experiencia vital y la consecución de una vida terrenal estable que lleve a una mejor vida eterna, la muerte inicia una serie de procesos y decisiones de carácter cotidiano $^{45}$ y automatizado. La pertenencia a las cofradías está presente en numerosas disposiciones testamentarias, a través de las cuales se favorecen las parroquias asociadas con el encargo de misas y las obras que la cofradía favorece, encargando a los cofrades la distribución de limosnas y mandas, y solicitando que el difunto sea enterrado en el hábito de la orden del santo bajo

41. ACSD, 2/22, transcrito en SÁENZ TERREROS, $M^{a} V^{a}$, El hospital..., pp. 89-90.

42. ACSD, Libro de Fábrica, 22/35, 28/08/1523.

43. SÁENZ TERREROS, $M^{\mathrm{a}} \mathrm{V}^{\mathrm{a}}$, El hospital..., p. 65.

44. AMLo, ILA, 6, ff. 1v-2r, Inventario de los Papeles pertenecientes al Santo Hospital 1771.

45. Véase, GARCÍA FERNÁNDEZ, Máximo, "Cultura material y religiosidad popular en el seno familiar castellano del siglo XVIII", en Cuadernos Dieciochistas, № 5, Salamanca, 2004, pp. 97-121. 
cuya advocación se establece la cofradía, los gastos funerarios consumirán importantes cantidades de los recursos de estas asociaciones.

No puede considerarse que las cofradías promovieran como su objetivo primario el establecimiento de servicios asistenciales o favorecer una sociedad más humanitaria. Si bien desde su origen y por cuestión religiosa el favor a los pobres se benefició de sus esfuerzos no existe un concepto de asistencia o mejora de las instituciones a medio o largo plazo y toman rápidamente un carácter similar al de los gremios. Los beneficios son empleados para la mejora de las parroquias y celebraciones internas, compitiendo entre ellas por el ornato y la relevancia de su parroquia frente a las demás de la localidad ${ }^{46}$. La búsqueda de preeminencia y los excesos dará lugar a que a partir de mediados del siglo XVIII estas prácticas Ilamen la atención del obispado y atraigan fuertes críticas y regulaciones jugando un importante papel en su declive junto con la creación de las Juntas de Hospitalidad y Beneficencia que concentrarán el control de los recursos que eran entregados o producían rentas para los hospitales. También la administración municipal deberá actuar ante los abusos, en Calahorra en $1599^{47}$ se solicita a las cofradías que reporten el gasto que reservan para las celebraciones internas de los cofrades, las suspendan, y entreguen esas cantidades a los pobres, esta medida se realiza en el contexto de la peste, pero también de sequía y hambruna y anteriormente ya se prohibió a la Cofradía de la Misericordia en 1584 pedir limosna para los pobres vergonzantes puerta a puerta, debiéndose limitar estas peticiones a las puertas de las iglesias, realizadas por individuos aprobados por el ayuntamiento ${ }^{48}$.

Aunque sólo fuera sobre el papel más que una verdadera declaración de intenciones, las cofradías establecerán en sus estatutos el concepto del socorro mutuo hacia sus miembros en caso de hallarse necesitados, que se extendía mediante colectas a la atención de los pobres que eran administradas por el prior de la cofradía, sin existir control de sus esfuerzos por otras instituciones como los concejos o las parroquias, aunque liberaban éstas últimas de cierta carga de responsabilidad sobre estos problemas. Las cofradías al mismo tiempo promovieron la introducción del concepto asistencial e impidieron su desarrollo al funcionar de un modo descoordinado e ineficiente.

46. SÁINZ RIPA, E., La Redonda... XVI-XVII..., doc. 530, p. 90, el canónigo de La Redonda de Logroño presentó un testimonio por la oposición de las cofradías parroquiales a que la Colegial llevará pendón en la festividad de San Marcos de 1561, terminaría abriendo un proceso apostólico en Roma en 1562 y posteriormente varias ejecutorias de Roma que disponen que el Cabildo de La Redonda ocupe la mano derecha en las procesiones en 1583 (docs. 786-788, p. 131), la cuestión continúa en el siglo XVII.

47. AMC, LAM 1599, sesión de 15 de Abril.

48. AMC, LAM 1584, sesión de 7 de Enero. 


\section{Los sistemas de financiación}

Los hospitales obtienen sus fondos principalmente de cuatro vías: rentas de bienes raices o censos adscritos, réditos de préstamos, donaciones de particulares, y privilegios concedidos por diferentes niveles de la administración. La financiación directa por parte de las instituciones públicas o religiosas es escasa, es posible encontrar censos cargados a la ciudad o centros religiosos, pero resulta complicado rastrear el censo original para conocer el motivo que llevó a su otorgamiento. Ibáñez Rodríguez sugiere unas rentas totales de la Diócesis de 24,5 millones de mrs. hacia 1540, de los que 128.622,5 (0,5\%) corresponden a los hospitales, a lo que habría que sumar las aportaciones del arciprestazgo o parroquia concreta, las rentas (media de 2.500 mrs.) y donaciones. La media de la renta variaba tremendamente entre los diferentes hospitales, limitándose en algunos de los menores a $102 \mathrm{mrs}$. (una fanega de trigo en $1540^{49}$ ), siendo los mejor parados en La Rioja el Hospital de la Abadía (12.000 mrs.) y el Hospital de Haro (6.000 mrs.), frente a los 33.311 mrs. del Hospital de San Juanes en Bilbao ${ }^{50}$.

A través de libros de cuentas ${ }^{51}$ y fondos judiciales pueden observarse algunos de dichos métodos, aunque los documentos suelen limitarse en recordatorios y/o acuses de recibo sin concepto del pago, por lo que en algunos casos no puede afirmarse si es por servicios, censos o testamentos, del mismo modo no figura si es una deuda a título personal o si el individuo actúa como representante de una institución o cabezalero testamentario; o si los conceptos se refieren a varios motivos reunidos bajo su responsabilidad. Este sistema presenta el problema de la inestabilidad e irregularidad de las fuentes de recursos en cuanto se refiere a donaciones periódicas, rentas y censos, dependientes de la capacidad y aquiescencia de los deudores, provocando un gran número de pleitos y pedimentos de ejecución que a su vez llevan a gastos legales.

49. Los cálculos se refieren como estándar a la producción potencial, resulta más complicado obtener el valor de cultivos como las viñas, también abundantes en la región pero mayormente en manos particulares, por ejemplo el hospital de Arenzana de Abajo, dependiente administrativamente de Santa María La Real, obtiene en 1584 sus rentas de 23 obradas de viña y 11 celemines de tierra (AHDLo, Arenzana de Abajo 9, 22/08/1584, en, IBÁÑ̃EZ RODRÍGUEZ, S., "Hospitales del Camino...).

50. IBÁÑEZ RODRÍGUEZ, S., "Hospitales del Camino..., p. 315; Como referencia, MARTÍNEZ GARCÍA, Luis, "El albergue de los viajeros: Del hospedaje monástico a la posada urbana", en DE LA IGLESIA DUARTE, J.I. (coord.), IV Semana..., p. 83, ofrece las rentas de varios hospitales de Burgos a finales del siglo XVI, el Hospital de San Lucas (10.000 mrs. y unas 200 fanegas de grano), Santa María La Real (30.000 mrs. y 200 ff.) y uno de los grandes hospitales de Patronato Real, el Hospital del Rey $(1.600 .000$ mrs., 7.000 ff. de grano, 300 ff. de sal y unas 6.500 cabezas de ganado lanar).

51. En Logroño se dispone de AHPLR, DP 223/1, continúa el "Libro Viejo de los Fenecimientos", que no se conserva pero se relaciona con AHPLR, PN 980/6. En el AHPLR se hallan libros de otros hospitales. 


\subsection{Ingresos por censos y rentas}

El establecimiento y vinculación de censos, está ligado principalmente a tres motivos: disposiciones testamentarias, condiciones de compra, y pago de préstamos; con carácter temporal o perpetuo. Un número de ellos se establecen como donaciones benéficas, pero es discutible la intención benéfica de posteriores censaleros, ya que está vinculado a la propiedad, la voluntariedad reside en acceder a hacerse cargo de este pago, pero no puede afirmarse que se mantenga el interés en financiar a las instituciones. La institución que se beneficia tiene derecho sobre la propiedad en caso de rotura del contrato, y en ocasiones no se realizaban en los traspasos todas las diligencias de forma correcta $^{52}$. Las condiciones del censo obligan al censalero y a sus herederos con un aval o todas sus posesiones, por lo que especialmente en el caso de tierras, una enfermedad o debilidad prolongada, así como sequías o plagas, tenía el potencial de arruinar al enfermo o a su familia en caso de trabajarlas ellos mismos, provocando que las mismas instituciones benéficas formaran parte del problema de la expansión del pauperismo ${ }^{53}$. En casos de impago el pleito podía llevar a la expropiación, en cuyo caso su propiedad recaía sobre la administración del hospital siendo tratadas en ocasiones como propiedad privada por el administrador con el consecuente perjuicio hacia el establecimiento, incluyendo errores o malversaciones por las que estas propiedades se asignaban a otras instituciones dependientes de la administración concreta o se veían afectadas por reestructuraciones como la absorción o defección de parroquias con respecto a la principal ${ }^{54}$.

52. En la documentación del Hospital de la Abadía puede encontrarse una situación al respecto, con el traspaso de una serie de propiedades cargadas con censos a diferentes individuos por parte del Bachiller Navarro (o Naharro) sin haber sido informados los compradores o el hospital, cuyo permiso es necesario por disposiciones contractuales del otorgamiento lo que obliga a los nuevos propietarios a ratificar el censo ante la amenaza de problemas legales y pérdida de la propiedad.

53. Los censos incluyen cláusulas del tipo: "a todo su riesgo e ventura de piedra, nyebla, yelo, secá, gusano, agua de riego e otro caso fortuyto pensado o no pensado que dios se a serbido de dar, que por hello no sea visto hacérsele desquento alguno deste censo", extraído de un pleito en el que Antonio de Belorado solicita al Hospital de la Abadía quedar libre del censo por enfermedad que le imposibilita para trabajar la propiedad en 1572 a raíz de la petición de ejecución por impago de 28 ffs. sobre 16 de censo anual. Es enajenado a su hijo Juan (AHPLR, DP, 224/2, f. 17, escribanía de Juan de Sevilla). En ocasiones los censos eran suspendidos o modificados según circunstancias. La misma administración modifica un censo: "De estas dos fanegas de trigo deste contrato no a de pagar $\mathrm{P}^{\circ}$ Cordero ni sus herederos mas de una fanega porque la otra fanega se le quita por razon que fue vista la heredad por los señores abad, prior y mayordomo y pareció haberse llevado el rio un pedaco de tal manera que lo que llevo quedo hecho cascajal y sin fruto" (AHPLR, DP, 224/2, f. 34, s.d., escribanía de Juan de Sevilla).

54. Entre los años 1598 y 1601 se observa en las cuentas de deudas del hospital de Nájera: "Adviertese que los clerigos de la cruz metieron una casa que hera del ospital en la Yglesia 
La mayor parte de los censos perpetuos en la documentación, son traspasos y ratificaciones por la herencia o venta de la propiedad que requieren la elaboración de nuevos documentos reflejando la aceptación del nuevo censalero, generalmente unidas a pleitos por pedimentos de ejecución por corrimiento o las reuniones de información hipotecaria tras la creación de las contadurías de Hipotecas en 1768 por iniciativa de Campomanes y Floridablanca, y la orden del Consejo de Castilla en 1774 como puede verse en Nájera ${ }^{55}$. Desgraciadamente no suele figurar el establecimiento original, que no necesariamente se debe a una donación, en ocasiones se relaciona con condiciones acordadas para la concesión de un préstamo por parte de las instituciones benéficas para la compra de las tierras sobre las que se otorga el censo, o el impago del mismo.

Los censos y rentas propias se convertirán en una de las fuentes de financiación básicas del sistema hospitalario benéfico, como corresponde a una región que permanecerá estancada en un sistema productivo autárquico de base agraria hasta prácticamente el siglo XX caracterizado por las propiedades de pequeña extensión y muy repartidas. La Iglesia, y por tanto sus hospitales, será uno de los mayores propietarios de tierra, aunque se evitará la creación de latifundios que se observa en otras regiones, por lo que no es extraño que incluso pequeños hospitales muestren el derecho a cobro sobre docenas de propiedades, mientras que incluso los de tamaño medio como el Hospital de Grañón perderán cientos de propiedades durante las desamortizaciones ${ }^{56}$. Esto determina que el beneficio de los censos suela ser de escasa cantidad, excepto en los casos en los que el terreno forma parte de un mayorazgo donado a beneficio de instituciones asistenciales permitiendo un control más efectivo. Normalmente los ingresos se sitúan entre 3 celemines y una fanega, los redimibles a cambio o mediante dinero muestran cantidades semejantes, como un censo otorgado al Hospital de Logroño por parte de Juan de Briviesca sobre una viña que renta 150 mrs. anuales en 1561, cifra escasamente superior al precio de la fanega en aquél momento ${ }^{57}$.

de la cruz" (AHPLR, DP 227/2). En el mismo hospital una ejecución de un censo se soluciona con la adjudicación de las propiedades a la Abadía y por extensión al abad en lugar de al Hospital (ARChV, Registro de Ejecutorias, 2586/6), y a su muerte el arcipreste Juan Hurtado de Cabredo entrega 21 obradas de viña, que se originan en este pleito y pertenecen a la Abadía, a su nieta Inés Hurtado de Cabredo, incluyendo el establecimiento de un censo a favor del Hospital por 1 fanega y 4 celemines de trigo (AHPLR DP, 224/2, f. 137).

55. AHPLR DP 224/2, Libro de escrituras de censo y ratificaciones (1572-1595), recogidos en 1775.

56. AHPLR, Judicial, 27/5, 208 subasta pública en el BOPL número 437 (17/06/1860).

57. SÁINZ RIPA, E., La Redonda...XVI-XVII..., doc. 529, p. 90, 19/04/1561, escribanía de Juan de Entrena. 


\subsection{Limosnas}

Otra de las fuentes de ingresos de las instituciones asistenciales con un carácter inestable que depende de la época del año y la coyuntura económica sería la recolecta de limosnas. Autores como Sáenz Terreros proponen las donaciones y limosnas como muestra de solidaridad o "espíritu humanitario" 58 . Dado que los individuos conocen bien las consecuencias de la pobreza, la enfermedad y la guerra, se genera un sentimiento de unidad en la población. Ruiz Capellán y Lastres Mendiola también defienden la idea de la solidaridad que lleva a la asistencia social en la Edad Moderna, consideran que "se da por supuesto" que desde el siglo XVI existe voluntariado para el trabajo en los hospitales, en especial por parte de los $\operatorname{cofrades}^{59}$. Se señala el elemento religioso como potenciador, ignorando la motivación individual de la consideración social que se desprenden de la caridad y la de evitar las consecuencias espirituales que se desprenden del miedo a la muerte y al castigo divino. Se tiende a hablar con demasiada facilidad de la solidaridad y la asistencia mutua desde el siglo XVI pero principalmente debe atribuirse al fervor religioso, el estatus y la paz social, antes de poder hablar de estos conceptos. Incluso si la idea existiera a nivel filosófico, el humanismo tarda en calar en el ideario de la sociedad fuera del entorno intelectual. Aunque pueden mencionarse los movimientos comuneros como el germen de estas ideas en la población no puede considerarse que exista la conciencia de clase o la unidad fuera del área de influencia directa del individuo, o de igual modo se puede rechazar el alcance de las intervenciones de la población rural frente al control del poder e inmovilismo social por parte de la nobleza, la Iglesia y las élites urbanas ${ }^{60}$.

El control de las limosnas por parte de la Iglesia no únicamente está motivada por la ganancia económica, también la establece como juez intermedio capaz de ofrecer una medida de salvación o reducción de las consecuencias de los pecados terrenales e incluso la posibilidad de redención de condenas, como la excomunión $^{61}$, por lo que procurará mantener el control sobre las recolectas, que se multiplican en el caso de las grandes bulas en las que el control de las ganancias no recae sobre los recolectores y podían impedir o reducir sus beneficios habituales ${ }^{62}$. Como regulación se establece la necesidad de licencia para reunir las limosnas en forma de bulas o impetras para legitimar las recolectas, que suelen incluir el derecho a una parte o la totalidad de las

58. SÁENZ TERREROS, $M^{a} V^{a}$, El hospital..., p. 14.

59. RUIZ CAPELLÁN, Alberto, LASTRES MENDIOLA, Julio César, Hospital de Peregrinos y Pobres de Santo Domingo de La Calzada. Aspectos Sanitario-Administrativos, Logroño, 1995.

60. GÓMEZ URDÁÑEZ, J.L., LORENZO CADARSO, P.L., "Las comunidades rurales..., p. 86.

61. LÓPEZ DE SILANES, C., SÁINZ RIPA, E., Colección... (1400-1450), doc. 157.

62. El provisor del obispado de Calahorra será denunciado en 1479 por retener las limosnas de la Bula de Canarias por el Nuncio Apostólico, recogidas para la conversión (AGS,RGS,LEG,147912,35). 
recaudaciones obtenidas en determinadas iglesias o ermitas por parte de la institución favorecida, aunque también implican que ésta se hace cargo de su mantenimiento. Su efecto podía limitarse a una localidad o petición concreta como utillería para uso en los hospitales, aunque podían permitir la demanda de varios conceptos, no resultan extrañas las entradas del tipo "mas me ago cargo de treynta y un reales que se allegaron de limosna el dia que salieron a pedir ropa para el dicho ospital"63, con el objetivo de procurar evitar la petición de limosnas fuera de su control o de manera fraudulenta.

Estos permisos también eran concedidos por la Corona principalmente a favor de las grandes instituciones y aplicándose a todo el reino, como es el caso del Hospital de Nuestra Señora de Gracia de Zaragoza en $1504^{64}$ o en 1489 al Hospital de Santo Domingo "para que puedan demandar limosna para el hospital de Santo Domingo de la Calzada, a petición del dean y cabildo de dicha iglesia" ${ }^{\prime 65}$. Estas licencias reales son muestra del apoyo de la realeza a las instituciones asistenciales tras iniciarse el largo proceso de secularización de las mismas.

El Archivo de la catedral de Santo Domingo contiene varias bulas e impetras referidas a la recolecta de limosnas por parte de la Iglesia de Santo Domingo y el Hospital de Peregrinos, así como Reales Provisiones ligadas a las visitas de reyes que las ratifican ${ }^{66}$. Sáenz Terreros refiere varias que legitiman la recogida de limosnas y las asociaciones que lo tienen permitido en el siglo XVI (principalmente la cofradía) en nombre del Santo Hospital en 1545 por Impetra del Obispo Juan Bernal de Luco aunque estas licencias no se limitan a recoger a favor de los hospitales, sino que piden a favor de la iglesia y hospital como conjunto, dependiendo de la correcta gestión de las mismas. Mayor interés tiene la Impetra del obispo Juan de Ortega en 1502 que regula la recolecta de limosnas a favor de la Iglesia y el Hospital de Santo Domingo:

A todos los arciprestes, vicarios e curas, e clerigos e capellanes e nobles e virtuosas personas seglares [...] nos fue dicho e dado a entender los grandes dapnos [sic] que se han causado e de cada dia viene a la casa e Ospital [...] a causa de las cautelas, tomas e encubiertas que se hacen e cometen en las yglesias [...] conviene a saber por los maniobreros e otras personas dellas, en los vacines del dicho Ospital de Señor Sancto Domingo tiene en todas las yglesias deste dicho nuestro obispado, por imposicion antigua, por virtud de las gracias e bullas e indulgencias e perdones [...] la quarta parte de todas las impetras, asi de la Redempcion de los cautivos como de otras qualesquier que andoviesen

63. AHPLR, Beneficencia, 35, f. 40r, 1609 Hospital de San Salvador de Navarrete.

64. AGS, CRC, $755,4 / 39$.

65. AGS, RGS, LEG, 148901, 388.

66. ACSD, 22/44 Carlos I, 1542; ACSD, 22/57 Felipe II 1592, ACSD, 22/21 Felipe III 1606. 
de cada año [...] algunas personas dan formas e maneras, que contra lo antiguo e acostumbrado, sean impedidas las limosnas del dicho vazin de Señor Sancto Domingo, dando logar que anden otros vazines asy de hermitas como de otras demandas, que de razon no debian ni deben andar, ni queremos que anden salvo el vazin de la tal ciudad [...] exortamos e amonestamos a todos y a cada uno [...] seades osados vos nin alguno de vos mandar facer ni fagades toma ni encubierta alguna [...] ni aya fraude en cosa alguna que sea dado para ello, [...] pues es cierto e sabeis que es para la obra e pobres del dicho Ospital, las limosnas que por los fieles cristianos son mandadas dadas o dejadas. [...] E algunas personas [...] lo toman para sus yglesias e fabricas e para otros reparos [...] Pues esta claro en derecho que la madre siempre debe ser preferida a todas las otras yglesias sujetas a ella. [...] e lo cumplid so las penas e censuras [...] so pena de suspension de oficios e beneficios a los clerigos [...] e de excomunion mayor a los legos ${ }^{67}$.

Resultan evidentes los conflictos derivados de disposiciones semejantes, las colectas se realizan y gestionan en las principales iglesias, reduciendo las ganancias de las parroquias y cofradías con pequeños hospitales y convirtiéndose en otro factor que contribuye a su insostenibilidad, aunque facilitaría la formación de hospitales de mayor importancia. Hasta el siglo XVIII la presencia de diferentes Órdenes en ciudades como Logroño no varía y la dispersión de los recursos obtenidos por las mismas supone similar problemática. En el siglo XVII únicamente se menciona a los Carmelitas Descalzos, y ante la competencia se logró que la administración logroñesa les prohibiera la petición de limosna en la jurisdicción de la ciudad ${ }^{68}$.

En algunos hospitales se encuentran asociadas ermitas en las que se colocan cepillos, lógicamente las mayores cantidades están ligadas a las diferentes fiestas y eventos litúrgicos. En las cuentas del Hospital de Navarrete a principios del siglo XVII se refleja esta práctica en "las hermitas que esta billa tiene anexas al ospital"69. Las limosnas recogidas se sitúan en torno a los 20-100 mrs. para los días señalados o domingos, destacando la advocación de Nuestra Señora del Prado (22 de mayo) en la que llegan a superarse los $200 \mathrm{mrs}$. Existen notables excepciones ligadas a fiestas de mayor importancia como Viernes Santo y Pascua que supera los mil maravedíes y Ilega a acercarse a los dos mil, sin duda por el mayor grado de devoción asociado y la posibilidad de ostentación ante los demás feligreses. Otros días notables de recaudación son las ferias regionales como la de San Miguel de Nájera, que igualan

67. ACSD, 22/18, 1502, transcrito en SAENZ TERREROS, Mª V ${ }^{a}$, El Hospital..., doc. 4, pp. $90-92$

68. AMLo, LAM, 1645, sesión de 26 de Mayo.

69. AHPLR, Beneficencia, 35/1, se citan entre otras las de San Llorente, Nuestra Señora del Prado, San Cristobal, San Roque, Santo Antón y la Madalena, Santo Dolines y San Miguel. 
las limosnas del día de Nuestra Señora del Prado, en septiembre de 1612 "coxiose en nuestra señora de prado de los que yban a la feria de nagera ducientos y catorçe mrs.", el año anterior se llega a los 266 mrs., superando ligeramente el precio de la fanega de trigo (240-256 mrs.). El total anual se encuentra en torno a los 5.0007.000 maravedíes, Ilegando a suponer más de un 10\% de los ingresos anuales del hospital y suficiente en algunos años para costear totalmente el gasto asistencial dedicado a los pobres enfermos.

TABLA 1. Relación de limosnas del Hospital de Navarrete (en mrs.) ${ }^{70}$.

\begin{tabular}{|c|c|c|c|}
\hline Año & Total Anual & V. Santo y Pascua & Cargo Anual \\
\hline 1609 & 4.999 & 1.156 & \\
\hline 1610 & 4.962 & 1.513 & \\
\hline 1611 & 6.176 & 918 & \\
\hline 1612 & 5.123 & 1.190 & \\
\hline 1613 & 6.634 & 1.224 & 63.609 \\
\hline 1614 & 7.273 & 1.530 & 50.770 \\
\hline 1615 & 6.327 & 1.870 & \\
\hline 1616 & 5.767 & 890 & 49.875 \\
\hline 1620 & 4.996 & - & 41.870 \\
\hline 1624 & 5.296 & - & 43.174 \\
\hline 1625 & 5.216 & - & \\
\hline
\end{tabular}

Estos ingresos no están libres de carga, como beneficiario el hospital se hace cargo de las ermitas, debiendo emplear parte de sus recursos en la fábrica y ceremonias, así como en material litúrgico, en 1609 se gasta en reparaciones y acondicionamiento de las ermitas más de 40.000 mrs. ${ }^{71}$, superando los ingresos obtenidos tanto por limosnas como por censos y rentas. La adscripción de estas ermitas se realiza por disposición del Obispo Pedro Manso de Zúñiga, esta disposición, además de formar parte del proceso de unificación de hospitales que se aceleró tras la peste de 1599, responde también al conflicto que la diócesis mantiene contra las Órdenes Hospitalarias en el control de la atención a los peregrinos, en concreto por influencia del Hospital de San Juan de Acre, aunque ya se encontraba en declive ${ }^{72}$. Los pleitos también afectan a otros

70. AHPLR, Beneficencia, 35/1.

71. AHPLR, Beneficencia, 35/1, ff. 56r-58v.

72. LARRAURI REDONDO, S., LOSANTOS BLANCO, S., Los Hospitales del Camino..., pp. 156-175, describe los conflictos con los diferentes obispos que se extienden hasta el siglo XVIII. 
concejos de poblaciones que colaboran con el mismo en calidad de patronos y administradores, especialmente Fuenmayor ${ }^{73}$. El Hospital de Navarrete obtiene el beneficio resultante de la venta de las propiedades de las ermitas y con ellas las del Hospital de las Tablas, relacionado con la ermita de Santo Dolín por un total de $102.338 \mathrm{mrs}^{74}$.

Lógicamente a mayor tamaño de la población las recolectas crecerían, aunque las demandas eran realizadas por un mayor número de instituciones. Entre 1650 y 1656 el Hospital de Logroño ingresa una media de 5.586 mrs. anuales de limosnas, en su mayor parte obtenidas en Jueves y Viernes Santo, pedidas para "ayuda de la çera de los monumentos" de limosnas regulares en los siete años. Aunque la petición para cera consumida en rituales religiosos resulta ridícula para el punto de vista de la asistencia actual no puede obviarse que bajo las creencias operantes en la época las rogatorias y misas podían formar parte de los servicios considerados necesarios para el restablecimiento tanto del cuerpo como del alma.

\subsection{Donaciones}

Las donaciones testamentarias suelen ligarse a un objetivo determinado cuando no se entregan incondicionalmente a la institución, en este punto entran en consideración los intereses individuales influenciados por la pertenencia a cofradías o las indulgencias asociadas a algún fin. Por ejemplo en 1638 por el testamento de Jerónimo de Lagunilla se entrega a Francisco de Barrón, regidor de Logroño 100 ducados para el Hospital de la Misericordia y otra manda para ayuda de los pobres de la cárcel ${ }^{76}$, en cambio en 1613 el propio Mayordomo del Hospital, García de Llerena funda con su testamento una capellanía en La Redonda $^{77}$, en 1659 se establece un salario de cien ducados para el capellán del hospital frente a los 300 reales mas dos reales por misa que se pagaban anteriormente por donación testamentaria de 300 ducados de Petronila de Albelda para la dotación del mismo ${ }^{78}$.

73. ARChV, Registro de Ejecutorias, 1716/20, 16/05/1592, escribanía de Quevedo, Ejecutoria del pleito litigado por el Concejo de Fuenmayor con los concejos de Entrena y Medrano sobre derecho a la administración del patronato del Hospital de San Juan de Acre, de Navarrete.

74. AHPLR, Beneficencia, 35, ff. 39v-40r.

75. AMLo, LAM, 1657, sesión de 19 de Junio.

76. SÁINZ RIPA, E., La Redonda...XVI-XVII..., doc.1.890, p. 296, escribanía de Pedro Íñiguez de Endérica.

77. SÁINZ RIPA, E., La Redonda...XVI-XVII..., doc.1.317, 02/03/1613, escribanía de Lupercio Rodríguez.

78. AMLo, LAM, 1659, f. 552v, sesión de 18 de Julio. 
Muchas de las donaciones, en especial las humildes, se limitan a material para uso del hospital como camas o ropa de cama ${ }^{79}$, el valor de estos materiales no puede ser menospreciado, el gasto en tela de los hospitales por desgaste y limpieza puede alcanzar cifras importantes ${ }^{80}$. Gracias a las pequeñas donaciones de individuos y las recogidas limosna en forma de ropa y telas viejas los hospitales podían contar con un suministro relativamente estable, sin embargo en los grandes hospitales son habituales de una forma al menos bianual las compras de "linçuelos" para la fabricación de ropa de cama, así como de lana para rellenar colchones. Estos gastos rondan los 5.000 mrs. tanto por el material como por la elaboración, no siempre especificando la cantidad de material obtenida. De igual modo se encuentran donaciones de otros materiales necesarios, como leña o aceite para la iluminación y calefacción, en la práctica muchas de estas mandas serían abonadas mediante el precio de los materiales a los que se refiere la donación.

En ocasiones necesidades puntuales motivaban para realizar donaciones, lo que será especialmente relevante en los periodos de crisis como las epidemias de peste del siglo XVI o la generalizada crisis de subsistencias del siglo XVII, que afectará duramente a La Rioja por su dependencia del sector agropecuario. Durante estas situaciones las donaciones tienden a dirigirse a recursos necesarios para la respuesta a nivel municipal, mientras que los hospitales se benefician de las donaciones para gastos extraordinarios, como la otorgada ante la gran afluencia de soldados irlandeses que volvían de las campañas en Portugal y fueron atendidos en el Hospital de Logroño en el siglo XVII. José de Ocio, Caballero de la Orden de Santiago, dona 100 ducados "para el socorro y alimentos de los soldados que en el dicho hospital se recibieron enfermos ${ }^{\prime \prime 1}$.

Resultan de interés, por cuantía y efecto sobre la opinión pública, las donaciones testamentarias de las elites municipales y pagadas por sus herederos

79. Anteriormente a 1622 aparece en el inventario del Hospital de la Abadía "Un colchon que es de una manda que yço al ospital Antonio Ortiz de Çuñiga y de las almoadas [...] las dos mantas y dos savanas de la misma limosna" (AHPLR, DP, 225/1, f. 7r.), en el Hospital de Logroño se recibe "una cama de ropa" por testamento de Magdalena Navarro (SÁINZ RIPA, E., La Redonda ...XVI-XVII..., doc. 2.367, p. 368). La donación de camas tomaba en ocasiones el carácter de Obra Pía, acompañándolas de una dotación anual que debía emplearse para el mantenimiento de la cama y los gastos derivados de su ocupación, como la donación en 1590 a Rocamador de Diego de la Estrella de "una cama que valga doze Ducados para la enfermeria, y quinientos mrs. de Renta anual para su subsistencia" (AMLo, ILA, 6, f. 5v).

80. AHPLR, DP 223/1, ff. 26v-28r., en el inventario del Hospital de Rocamador de 1560 figuran 108 sábanas, 83 nuevas y 25 viejas que quedaron del año anterior, las restantes de las 158 del año anterior, las viejas eran empleadas como mortajas para los pobres de los que no se hiciesen cargo las parroquias.

81. AMLo, LAM, 1657, f. 289v, sesión de 19 de Junio, corresponde a 1653, en el que el gasto del hospital monta 60.461 mrs., se atendió a más de cuarenta soldados (AMLo, LAM, 1657, f. 313v.). 
o albaceas, generando en ocasiones deudas y pleitos que se extienden a lo largo de varios años ${ }^{82}$. Con los cambios de la crisis feudal surgen en La Rioja familias ajenas a la nobleza que obtienen sus fortunas del comercio y las emplean para acumular gran número de bienes raíces, e introducirse en la estructura de poder municipal siendo común encontrarlos ocupando diferentes cargos públicos, desde escribanías al regimiento. Se relacionan con las cofradías importantes, a pesar de encontrarse con la oposición de productores y mercaderes, carentes de los recursos necesarios para oponerse, y de la baja nobleza que veía su influencia disminuir, siendo sustituidos por estos arribistas que adoptaron sus costumbres y estilo de vida, con un notable efecto en las políticas matrimoniales y las muestras de piedad y caridad a través de Obras Pías. Su control sería retenido por los beneficios que se obtenían de las posesiones incluso después de cumplidas las mandas asociadas, y en muchos casos sus administradores se unirán al patronazgo administrativo de las instituciones beneficiadas, cuando no forman ya parte de él, dado que en muchos casos son asociadas a capellanías que ya participan en el control del establecimiento. Las grandes fortunas de estas familias y la formación de mayorazgos favorecía la declaración de herederos universales en el caso de revertir sobre instituciones asistenciales con el objetivo de no dividir las posesiones, pero a cargo de estos mayorazgos podían ir ligadas Obras Pías más específicas que obligaban al mantenimiento de ciertos servicios o instalaciones a los establecimientos para continuar recibiendo las mandas, como la establecida por Diego de Yanguas de 400 ducados en Logroño a cambio de asegurar la presencia de un capellán para misas diarias ${ }^{83}$.

En Logroño destacan las donaciones de los Soria, los Yanguas y los Gaona, que se sumarían a los Enciso o los Navarrete como las más importantes familias de la ciudad. Sería la herencia dejada por Hernando Rodríguez de Soria y su mujer la que iniciaría el proyecto de Rocamador ${ }^{84}$, y los Yanguas mostraron su apoyo a la Iglesia de Santa María de Palacio, cuyo cabildo estaba muy implicado

82. El modelo de transmisión patrimonial riojano es un reflejo del castellano en cuanto a los patrimonios burgueses, particiones igualitarias entre los hijos, favorecido por el predominio de la pequeña propiedad. En las grandes fortunas se tiende al modelo navarro de heredero único para evitar la disgregación, mientras que los demás herederos obtienen pensiones vitalicias o un número escaso de propiedades que aseguren su manutención. Véase, BARTOLOMÉ BARTOLOMÉ, Juan Manuel, GARCÍA FERNÁNDEZ, M., "Patrimonios urbanos, patrimonios burgueses. Herencias tangibles y transmisiones inmateriales en la Castilla interior", en Studia Histórica: Historia Moderna, Vol. 33, Monográfico: La ideología de la Herencia: Valores materiales y culturales, Salamanca, 2011, pp. 29-60.

83. AMLo, ILA, 6, f. 11v.

84. AHPLR, PN 472, Cristóbal Rodríguez, 01/06/1532, transcrito en GOICOLEA JULIÁN, Francisco Javier, "La elite ciudadana de Logroño en el tránsito de la Edad Media a la Moderna: Las familias Soria y Yanguas", en Berceo, 150, Logroño, 2006, pp. 133 y ss., "el que heredare este dicho mayorazgo quedase perpetuamente patron del dicho ospital juntamente con los otros que de todos an derecho diez y no mas y el procurador mayor que es o fuese de esta çibdad, çinco de los cofrades de Romador e çinco de los que eran de los otros ospitales". 
en actividades de beneficencia. Los Soria continuarían beneficiando a las instituciones asistenciales sin olvidar su carácter de fundadores del Hospital de la Misericordia, un siglo después el Capitán Felipe de Soria lo nombra como heredero universal, incluyendo un censo de 600 ducados aplicado sobre sus casas principales que sigue activo en $1771^{85}$.

Dadas las cuantías asociadas, en especial en caso de continuar un cónyuge o hijos con vida, las mandas testamentarias podían llevar a extensos pleitos como en el caso del testamento de Juan Ruiz de Gaona y María Yanguas ${ }^{86}$ entre Pedro de Gaona y el Hospital de Rocamador que se alarga durante 17 años. Inicialmente se presenta el testamento de Juan Ruiz de Gaona en el que dispone una serie de acciones a realizar tras su muerte (1529), como su enterramiento en Santa María de Palacio con descripción de la misa y el panegírico y el reparto de alimentos a los pobres en el día de su entierro, así como miles de misas a distribuir entre otras parroquias y años con diversos montos y donaciones, del estilo "Yten mando dar ropa a los enfermos de la Yglesia de nra. Señora de Balcuerna myll mrs.". Pedro de Gaona, hijo de un matrimonio posterior, queda como heredero universal de su padre incluyendo los de María, que dejó todos sus bienes a los pobres tras su muerte en 1517, el proceso se abre para aclarar y demandar qué parte de la manda de María de Yanguas resta por pagar. El inventario realizado comprende bienes muebles, inmuebles, dinero, censos y deudas cobradas, etc. por valor de 867.298 mrs., a lo que restar parte de los bienes comunes al matrimonio y los legados a otras personas que son discutidos por el hospital, en total se calcula que María de Yanguas dejó al Hospital 339.340 mrs., de los que restan pagar 140.573,5 mrs. según cálculos que son confirmados por Ejecutoria de la Real Chancillería en $1558^{87}$, aunque es necesaria una segunda confirmación en 1562, y una tercera ejecutoria en $1567^{88}$. En cualquier modo se ofrecen ejemplos de diferentes disposiciones que afectan a diversas personas e instituciones ${ }^{89}$, destacando la financiación de actividades religiosas de diferentes iglesias y monasterios tanto en Logroño como en otros lugares de La Rioja, como "myll mrs. de censo perpeturo que

85. AMLo, ILA, 6, f. 6 .

86. AHPLR, Judicial, 927/7, 1550-1562, Logroño, escribanía de Pedro del Valle.

87. ARChV, Registro de Ejecutorias, 919/8, 17/06/1558, escribanía de Pedro de Palacios.

88. ARChV, Registro de Ejecutorias, 1114, 26.

89. AHPLR, Judicial, 927/7, 1550-1562, Logroño, escribanía de Pedro del Valle; "cinco myll mrs. que mando para ropa a los frailes de sant Francisco [...] Yten cinco myll mrs. que pago Diego de Yanguas a los frailes de Valcuerna para ropa [...] Ytem Treynta myll mrs. en que tasamos las Diez fanegas de trigo perpetuas que mando la difunta para el hospital [...] ducado y medio que mando para carne al hospital [...] diez myll mrs. que pago Diego de Yanguas en ropa para el hospital [...] quinze myll mrs. por los seiszientos mrs. de censo perpetuo que mando a la cofradia de sant Martin. Yten cinco myll mrs. que mando para casar quinze huerfanas [...] A la cofradia de Santa Clara por manda del testamento doszientos y setenta y cinco mrs. [...] a los frailes de Valcuerna tres ducados". 
mando a los Santos monasterios de Valvanera y sant Francisco para la cera del Sacramento", arreglo de deudas y pequeñas "limosnas" a individuos. María de Yanguas en su testamento dispuso que una vez se arreglaran las cuentas y derechos familiares "los demas Vienes suyos que permanecieren cumplido este testamento quiere que se den a pobres" y adelantándose al supuesto de que haya duda con respecto a estas intenciones, hace mención a disposiciones papales o "breves del papa", las mismas que sugeriría Pérez de Herrera ${ }^{90}$ como fuente de financiación, que alientan a que en caso de muerte sin herederos claros y en favor de la salvación del alma debería procurarse que los bienes reviertan a la Caridad por defecto, por supuesto siendo entregados a la Iglesia como administradora.

En el pleito de cuentas por partición de bienes del testamento de Francisco de Puelles en $1678^{91}$ se le identifica como cofrade del Santísimo Sacramento y la Santa Vera Cruz de Haro, a quienes deben pedírseles el "paño, attau y zera" para su entierro. Declara que el año de su fallecimiento se digan a cargo de sus bienes mil misas por la memoria de sus padres, mil por su tía y las otras diez mil por su alma, lógicamente resulta difícil de creer que pudieran celebrarse 12.000 misas en un año, son limosnas entregadas a diferentes parroquias y ermitas que suponen más de 25.000 reales, a las que añadir en cuanto a beneficencia "se vistan doze pobres [...] se les de Calzon y Ropilla y medias de un paño hordinario", también se perdona alguna deuda por ser el deudor pobre y entrega como donativo los beneficios obtenidos de su oficio público, que aparecerían en las cuentas del hospital como pagos por parte de la ciudad, "por quanto las prendadas [...] me toca la mitad del Valor de ellas como Alcayde [...] quiero se de a los pobres mas necesitados del estado jeneral de la dicha villa de Casa de la Reyna". A parte de estas limosnas nombra como heredera de sus bienes a su mujer, María Ruiz de Castillo, con la condición de que tras la muerte de ella y sin considerar a otros posibles herederos sus propiedades las "herede el Santo Hospital de la Madre de Dios desta dicha Villa para que con lo que Reditaren se puedan alimentar y asistir muy bien a los pobres que ubiere y se recojiesen en dicho hospital en sus enfermedades [...] carga el patronato de ellos a la Justicia, Cavildo y rejimiento desta dicha Villa"92. El inventario de los bienes del difunto se extiende por 104 folios incluyendo su casa de Haro y su palacio de Casalarreina, finalizando con unas cien propiedades. Sólo en efectivo y tasación de objetos, se arroja un montante de 87.497 rs. y 7 mrs. En los descargos aparecen otras mandas que Puelles realizó en vida como: "Y treszientos y sesenta y dos Reales de una arroba de zera blanca que el difunto

90. PÉREZ DE HERRERA, Cristóbal, Discursos del amparo de los legítimos pobres, Madrid, 1598.

91. AHPLR, Judicial, 1097/1, 10/03/1678, Haro, escribanía de Juan de Gogenola.

92. En 1683 aparecen confirmadas "las Com[uni]dades eclesiastica y secular como patronos del Ospital de la Madre de Dios" (AHPLR, Judicial, 1154/11). 
mando a la escuela de expositos" en que se paga la fabricación de esta cera por los expósitos para ceremonias religiosas, así como 1.334 rs. y 26 mrs. en ropa para los doce pobres antes mencionados. El interés del difunto por la religión queda patente en sus disposiciones, se menciona "treinta Reales a Pedro de Montaña de doze Bulas que se quedaron debiendo", pero resulta significativo que no quiera depender de su propia cofradía.

\subsection{Juros y Privilegios}

En el caso de apoyo Real sí es posible encontrar privilegios y concesiones, como el privilegio sobre la alcabala en Santo Domingo de $1.500 \mathrm{mrs}$. que se suma a los derechos de portazgo y pontazgo por concesión de los Reyes Católicos, posteriormente en 1541 también cobra una sisa sobre los comestibles. En Logroño, el hospital se beneficia de un censo perpetuo de 1.000 mrs. y dos gallinas "que la Ciudad lo paga sobre las casas que bende el aceite y pescado" ${ }^{93}$. Pueden encontrarse otros pagos de mayor importancia en el mismo ejercicio del Hospital de Logroño entre los años 1650 y 1656 procedentes de las alcabalas, en "los quatro Juros que el dicho ospital tiene sobre la merindad de esta ciudad [...] y con ello pagado la carne y medicinas que esta gastado en le dicho ospital", que suman en los siete años un total de 678.692 mrs., Estos ingresos son suficientes para suplir los gastos anuales, pero son sólo potenciales, en 1656 estos juros no se han pagado, adeudándose 96.956 mrs. Probablemente estos juros provienen del empleo de los recursos del Hospital durante las crisis de subsistencia que se suceden en el XVII, para la compra de alimentos con que suplir las necesidades de la ciudad que se convierte en la mayor preocupación y línea de actuación de las administraciones frente a estos eventos. Fuera de los momentos de crisis estos juros se establecen señalando un descuento o pago a cargo de recaudaciones que se destinan a la Corona, comunes a raíz de ocasiones especiales y celebraciones, pero también por ruego en tiempos de crisis, tomando tanto carácter temporal como perpetuo, como se observa en la permanencia de varios de ellos en el siglo XVIII en Logroño ${ }^{94}$.

La ordenación política y fiscal Moderna posibilita que miembros del Estado Noble, en particular Regidores y Corregidores Perpetuos, liguen beneficios a

93. AMLo, LAM, 1657, sesión de 19 de Junio.

94. AMLo, ILA, 6, f. 4r; "Un Juro de dos mil Maravedis á favor y en caveza de el Ospital de esta Ciudad situado sobre las Alcavalas de ella por privilegio de S.Al., su fecha en Madrid a 23 de Junio de 1570 [...] Otro Juro de Cinquenta mil mrs. [...] Unas Reales Cedulas para que al Ospital se le paguen los dos Juros arriva expresados enteramente y sin desquento alguno a consequencia de Real Orden de 5 de Abril de 1649 por la qual se dio reserva perpetua de medias partes y quartas partes a todos los Juros que estuviesen en Cavezas de Hospitales, Conventos de Religiosas, Redencion de Cautivos y los situados para celebrar fiestas del Santisimo Sacramento". 
sus testamentos. En ocasiones se recurre a la parte que les corresponde como recaudadores, pero al igual que la Corona o los altos cargos eclesiásticos se vinculan privilegios sobre las imposiciones municipales para beneficio de las instituciones asistenciales, fundamentalmente las alcabalas, colaborando a la problemática del sistema contributivo del Antiguo Régimen que impide el saneamiento y racionalización de las cuentas. Así en el Hospital de Logroño pueden encontrarse conservados algunos de ellos en el Inventario de Papeles de 1771, como la cesión de un juro de 7.131 mrs. por testamento de Juan Vélez de Loyola "sobre el uno por 100 de la Ciudad de Soria" ${ }^{\prime 95}$. Otros Juros similares son citados en el mismo Inventario situados sobre diferentes ingresos, en general alcabalas de diferentes localidades, se mencionan varios otorgados por disposición testamentaria de Alonso de Bustamante Torreblanca, Corregidor Perpetuo de Logroño y su mujer Dionisia Menéndez de Posadas sobre diversas recaudaciones, destinados a pagar "una sala de convalecientes que tuviese seis camas"

\subsection{Otras fuentes: difuntos, espectáculos y préstamos}

El estado precario de las finanzas y la escasa colaboración administrativa por parte de la estancada fiscalidad y de la administración eclesiástica, o la malversación de las cofradías obliga a que los establecimientos benéficos busquen otras vías como la venta de productos elaborados por los acogidos que también son un modo por parte de las parroquias de recuperar la inversión. Los hospitales también suman a sus ingresos las pertenencias halladas en los fallecidos, en parte como compensación para los gastos de enterramiento y la celebración de misas y funerales (revirtiendo en la propia institución en el caso de las religiosas). Esta práctica resulta más sencilla en el caso de pobres desconocidos o que mueren sin familiares que puedan reclamarlo, en el caso de hospitales con afluencia de peregrinos que no necesariamente eran pobres en el sentido de exclusión social, la cantidad podía ser importante dado que se encuentran alejados de sus casas y las instituciones corren un bajo riesgo de enfrentarse a reclamaciones ${ }^{97}$.

95. AMLo, ILA, 6, f. 4v., el Juro se establece en Madrid el 30 de Marzo de 1652.

96. AMLo, ILA, 6, ff. 5r-5v y 6v.; " $\mathrm{n}^{\circ} 27$ [...] Otro Juro [...] situado sobre las Alcavalas de Villaviciosa, Partido de Oviedo de 45.530 mrs. de Renta [...] Madrid a 3 de Diziembre de 1632 [...] $n^{\circ} 28$ Otro Juro de 68 Ducados [...] situado en Millones de Burgos, su fecha en Madrid a 8 de Diziembre de 1634. $\mathrm{n}^{\circ} 29$ Otro Juro [...] de 19.237 mrs. situado en el $2^{\circ}$ uno por 100 de Salamanca [...] Madrid 7 de Agosto de 1656".

97. ACSD, Hospital, Libro de Cuentas 1501-1542, en RUIZ CAPELLÁN, A., LASTRES MENDIOLA, J.C., Hospital de Peregrinos..., pp. 49-50; "rreçiby de un francés que morió en el hospital [...] sumó todo treçientos e sesenta e ocho mrs., que pagué destos dichos mrs., que se enterró en la clahustra [...] y por quatro mysas cantadas. [...] quedaron para el ospital doçientos e cinquenta e seys mrs.", también aparecen ejemplos de diversa importancia, como siete florines de oro, o un capuz de 600 maravedíes; o casos en los que el fallecido hubiera sido capaz de hacer testamento, "Yten se le açe cargo de doçientos y beinte y cinco reales [...] por los mismos que cobro de una 
Por posicionamiento físico del edificio o concesión municipal también pueden encontrarse ingresos ligados a espectáculos. En el caso de Logroño, el propio Hospital de la Misericordia forma parte de la Plaza del Coso, donde se celebran las corridas de toros, y por otra parte el patio interno del hospital es empleado hasta el siglo XIX como corral de comedias $^{98}$. A mediados del siglo XVII se recaudan alrededor de 700 reales anuales del alquiler de los espacios sobre la Plaza del Coso, a razón de cien reales por ventana para los toros, en las cuentas pertenecientes a los años 1650 a 1656 también se cobran 2.088 reales "en beçes que an benido compañias de farsantes y titeres", frente a los 95.400 mrs. producto del arriendo de los espacios sobre la Plaza del Coso.

Como modo de rentabilizar los ingresos también se recurre a la concesión de préstamos con una rentabilidad escasa y que se enfrentan a la volatilidad de la economía del Antiguo Régimen. En ocasiones estos préstamos son desvíos de fondos para el pago de necesidades urgentes, como durante epidemias o hambrunas ${ }^{99}$, pero normalmente figura como motivo la compra de terrenos o la apertura de negocios, lo cual podría considerarse un servicio asistencial contra la pobreza, en estos casos suele otorgarse un censo perpetuo a favor del establecimiento como condición contractual, pero los préstamos se convierten en la práctica en un riesgo con respecto a la malversación de fondos, concedidos a elites ciudadanas y en especial a los patronos y cofrades, aunque al mismo tiempo este servicio les ayude a atraer posibles donantes.

En el Hospital de la Abadía en el siglo XVII los beneficios obtenidos de rentas y donaciones son empleados para la concesión de préstamos a diferentes individuos, hallándose algunos de varios cientos de ducados. En el Hospital de Navarrete las cantidades empleadas en préstamos llegan a sumar cientos de miles de maravedíes anuales que se reinvierten inmediatamente en nuevos préstamos. Los años con un menor registro de ingresos por préstamos del Hospital de Navarrete montan unas cantidades entre los 4.730 mrs. (1613) y 6.800 mrs. (1614), otros años se alcanzan los 59.687 mrs. (1616) y 183.767 mrs. (1612), que no se reflejan en la atención a los enfermos o mejora de las instalaciones, ni en el cargo y descargo del gasto ordinario ${ }^{100}$.

limosna de una muger de nabarra que murio en dicho hospital" (AMLo, LAM, 1657, sesión de 19 de Junio, f. 289v).

98. AMLo, $1588-1590$, f. $69 \mathrm{v}$, pese a la resistencia del Obispo y considerándose las posibles molestias a los enfermos se colocaron paneles para aislar el ruido que llegaba de la plaza, así como un mirador para los ciudadanos importantes. Los papeles del hospital incluyen el arrendamiento de las ventanas y miradores por contrato, como en 1661 al Doctor Miguel Pérez de "una ventana o tablero de los que tiene el Ospital en el coso para ver fiestas de Toros en precio de 100 rs. cada año" (AMLo, ILA, 6, f. 3v).

99. Durante el siglo XVII se registran variaciones de precio de la fanega de trigo entre los 12 y 50 reales por fanega, véase LAZZARO RUIZ, M., GURRÍA GARCÍA, Pedro A., Las crisis de mortalidad en La Rioja (siglos XVI-XVIII), Logroño, 1989.

100. AHPLR, Beneficencia, 35. 
El Hospital de Rocamador de Logroño muestra un gran número de préstamos activos, a un $4-5 \%$ anual. Los mayores beneficios se asocian a los préstamos de menor cuantía, presumiblemente por que la mayor potencia económica posibilita redimirlos más rápidamente evitando el acúmulo de los intereses. De nuevo acudimos al ajuste de cuentas de los años 1650-1656, encontrando al propio Francisco Barron de Tejada, regidor de la ciudad quien redimió por completo un censo de 400 ducados (149.600 mrs.) en 1652, con 577 reales de réditos, y tiene activos otros dos censos por un total de 600 ducados de plata y un censo perpetuo de 220 mrs., por los que ingresa al hospital 97.443 mrs. en estos años, más preocupante es el préstamo concedido al Conde de Lemós de 8.000 ducados, para cuyo cobro deben desplazarse hasta su hacienda.

TABLA 2. Relación de censos redimibles del Hospital de Rocamador en 1657 (en mrs. $)^{101}$.

\begin{tabular}{|l|c|c|c|}
\hline \multicolumn{1}{|c|}{ Censalero } & Censos & Réditos & Pago Parcial \\
\hline Juan de Maridueñas & 243.100 & 35.411 & \\
\hline Francisco Barron y Texada & 149.600 & 19.618 & \\
\hline Pedro García de Vergara & 112.200 & 19.635 & \\
\hline Juan Ochoa de Mendieta & 187.000 & 30.413 & \\
\hline Juan Hernaez & 23.936 & 4.339 & \\
\hline Juan de Zuazo & 37.400 & 5.338 & \\
\hline Martín de Medrano & 112.200 & Activo & 13.464 \\
\hline Pedro de Yreguas & 93.500 & Activo & 37.400 \\
\hline Lucas Sáenz y Ana de Peña & 56.100 & Activo & 8.976 \\
\hline Juan de Amescu y su mujer & 117.810 & Activo & 23.500 \\
\hline Juan de Ojeda & 63.580 & Activo & 19.074 \\
\hline Diego López de Langarica y su hijo & 187.000 & Activo & 29.920 \\
\hline Juan de Armentia y su mujer & 74.800 & Activo & 18.700 \\
\hline Martín Pascual Loguero y Lorenzo Díaz & 17.952 & Activo & 7.992 \\
\hline La Florentina & 18.700 & Activo & 7.480 \\
\hline Juan Marin de la Monxia y Lucas Muro & 78.540 & Activo & 15.742 \\
\hline Licenciado Juan Sáenz de la Cuesta & 76.670 & Activo & 23.834 \\
\hline Juan de Salsas & 112.200 & 15.804 & \\
\hline Catalina Cerdan & 112.200 & Activo & 5.610 \\
\hline Isabel de Montenegro e Isabel de Barron & 48.620 & Activo & 12.115 \\
\hline
\end{tabular}

101. AMLo, LAM, 1657, sesión de 19 de Junio. 


\begin{tabular}{|l|c|c|c|}
\hline \multicolumn{1}{|c|}{ Censalero } & Censos & Réditos & Pago Parcial \\
\hline José de Castejón & 74.800 & Activo & 14.560 \\
\hline Juan del Cardo & 37.400 & 13.090 & \\
\hline Francisco de Urrue & 23.936 & Activo & 4.808 \\
\hline Juan Lobo & 37.400 & 14.960 & \\
\hline Juan de Leza y Juan del Valle & 37.400 & Activo & 14.960 \\
\hline Jerónimo de Larraga & 37.400 & 13.090 & \\
\hline Sebastián Caro & 37.400 & 13.090 & \\
\hline Francisco Fernández de Ocon & 37.400 & 16.830 & \\
\hline Miguel de San Pedro & 5.610 & 2.546 & \\
\hline Francisco de Lorca & 33.660 & Activo & 6.732 \\
\hline Martín de Muro & 7.480 & 5.610 & \\
\hline Conde de Lemós & 2.992 .000 & 194.820 & \\
\hline Francisco Maestro & 37.400 & Activo & 7.480 \\
\hline Francisco Pastor & 37.400 & 13.090 & \\
\hline
\end{tabular}

\subsection{Las rentas de los hospitales}

En su mayor parte la dispersión de la propiedad que caracteriza a La Rioja hace que los censos se apliquen sobre pequeños terrenos de una o dos fanegas, aunque hay una gran variación de tamaños entre tres celemines y diez fanegas. La pérdida y fragmentación de la documentación sumada a la variabilidad de la cotización del trigo y falta de rigor en la documentación dificulta el cálculo de las rentas con las que podían contar los diferentes hospitales ${ }^{102}$. El Hospital de Rocamador, sin referir la procedencia de la mayor parte de los fondos, sugiere una renta "de lo del general" de 32.393 maravedíes para $1559^{103}$ de los que únicamente identifica 9.940 mrs. ${ }^{104}: 4.238$ mrs. de diferentes censos y rentas,

102. IBÁÑEZ RODRÍGUEZ, S., "Hospitales del Camino...; para 102 mrs./fanega ofrece las rentas anuales de diversos hospitales diocesanos c. 1540, entre los riojanos encontramos: Alesanco (612 mrs.), Azofra (1.071 mrs.), Bañares (191,5 mrs.), Briones (1.000 mrs.), Canillas (255 mrs.), Cuzcurrita (343,5 mrs.), Enciso y aldeas (739,5 mrs.), Grañón (918 mrs.), Haro (6.000 mrs.), Herramélluri (204 mrs.), Leiva (115 mrs.), Medrano (816 mrs.), Nájera (La Abadía, 12.000 mrs.), Préjano (800 mrs.), Redecilla del Camino (2.106 mrs.), Rincón de Soto (2.265 mrs.), San Asensio (1.000 mrs.), San Vicente de la Sonsierra (1.800 mrs.), Sotés (2 hosp., 1.987 mrs.), Torrecilla sobre Alesanco (102 mrs.), Villalobar (102 mrs.).

103. AHPLR, DP 223/1, f. 25v.

104. AHPLR, DP 223/1, ff. 24v-25r, estas rentas son "del general en las personas que lo deban y en esta parte se pone lo que bien se cobra y en esta quenta lo perdido que Jamas se cobrara". 
2.000 mrs. por parte "de la ciudad"105, 2.000 mrs. de Pedro de Yanguas (por parte del testamento de su padre), $1.512 \mathrm{mrs}$. "de los censos que no se cobran de lo del general perdidos", y la falta de $190 \mathrm{mrs}$. para cuadrar estos $9.940 \mathrm{mrs}$. que deben sumarse a los 32.393 mrs., aunque el sumatorio es ligeramente superior, 42.739 mrs. ${ }^{106}$. Con una renta potencial de 30.000 a 40.000 maravedíes anuales el hospital de Logroño se convertiría en uno de los más grandes de la región, incluso comparado con los hospitales en Burgos y Bilbao, pero por falta de precisión no puede evaluarse el volumen de la deuda hacia el hospital, que podía acumularse en determinadas cuentas durante varios años hasta el pago o la ejecución judicial ${ }^{107}$.

En 1537 el Hospital de Peregrinos de Santo Domingo de La Calzada refiere haber recibido un total de 69.108,5 mrs. de los que sobran 900 que son entregados al Provisor Paz, aunque este alcance de cuentas debe incluir todo tipo de ingresos, no únicamente referidos a censos y rentas. Posteriormente en 15471548 en el alcance final suma $98.672,5$ mrs. en censos, y en el mismo libro del Hospital de Rocamador ${ }^{108}$, el sumatorio de 1568 arroja un total de 74.620 mrs., procedentes tanto de los censos como de ajustes de deudas. Aunque parezca que el hospital logroñés ya comienza a equipararse al Hospital de Peregrinos debe tenerse en cuenta que el último también contaba con cabaña ganadera, según el inventario de 1574-1575 dispone de 321 cabezas de ganado ovino, 16 de caprino y 16 de porcino ${ }^{109}$.

En el Hospital de San Salvador de Navarrete hay una mayor dependencia de los ingresos monetarios, años como 1614 únicamente refieren el ingreso de 28 fanegas y 10 celemines de trigo por un valor total de $17.646 \mathrm{mrs}$, aunque los ingresos por la venta del grano siguen superando ligeramente a los obtenidos en moneda. La toma de cuentas a Juan de Corral, mayordomo del hospital en los años $1609-1612^{110}$ arroja un cargo total de 465.331 mrs. frente a un descargo de 444.083 mrs., obteniéndose un beneficio de más de 20.000 maravedíes, como se mencionó previamente, el año 1609 se ingresan más de 140.000 mrs. de los

105. Desde mediados del siglo XVI ya pueden hallarse peticiones al Concejo de Logroño por parte del Hospital de Rocamador de las deudas habidas, AHPLR, PN 980/6 (1543).

106. AHPLR, DP 223/1, s.f., pese a estar situado al final del libro se ha foliado como "I."

107. ARChV, PL CIVILES, FERNANDO ALONSO (F), 611,3, Pleito de Hospital de Rocamador y Santiago, de Logroño (La Rioja), Sobre pedir el Hospital de Rocamador y Santiago, extramuros de la ciudad de Logroño, a Martín de Vergara 17.342 maravedíes que le debe, esta deuda se corresponde a 4 fanegas anuales que se han dejado de pagar durante años, según refieren las cuentas del hospital (AHPLR, DP 223/1, f. 3v) en 1559, y seguirá acumulándose "mas debe del año de 1559 y 606162 63".

108. AHPLR, DP 223/1, s.f.: se describen decenas de propiedades (casas, solares, huertas, viñas...) cargadas con censo en Logroño y poblaciones cercanas.

109. ACSD, Hospital, Libro de Cuentas 1569-1586, Inventario de 1574-1575, f. 92v, transcrito en RUIZ CAPELLÁN, A., LASTRES MENDIOLA, J.C., Hospital de Peregrinos..., pp. 63-68.

110. AHPLR, Beneficencia, 35, ff. 69 y ss., escribanía de Pedro del Busto. 
cuales únicamente 15.000 proceden de mandas testamentarias ${ }^{111}$, mientras que el resto proviene de los beneficios producto de las posesiones de las ermitas de las que se hace cargo el hospital.

Tabla 3. Cuentas del Hospital de San Salvador de Navarrete (en mrs.) ${ }^{112}$.

\begin{tabular}{|c|c|c|c|c|}
\hline Año & Censos y rentas & $\begin{array}{c}\text { Donaciones, } \\
\text { Jucios y ventas }\end{array}$ & $\begin{array}{l}\text { Cargo } \\
\text { Anual }\end{array}$ & $\begin{array}{c}\text { Descargo } \\
\text { Anual }\end{array}$ \\
\hline 1609 & 34.503 & 143.240 & & \\
\hline 1610 & 21.098 & & & \\
\hline 1611 & 24.387 & & & \\
\hline 1612 & 24.096 & 183.767 & & \\
\hline 1613 & 29.145 & 4.730 & 63.609 & 80.632 \\
\hline 1614 & 36.697 & 6.800 & 50.770 & 44.309 \\
\hline 1615 & 35.831 & & & \\
\hline 1616 & 33.493 & 59.687 & & \\
\hline 1617 & & & 68.061 & 48.906 \\
\hline 1618 & & & 63.162 & 56.762 \\
\hline 1619 & & & 48.524 & 41.122 \\
\hline 1620 & 37.477 & & 49.875 & 38.182 \\
\hline 1623 & & & 42.498 & 40.983 \\
\hline 1624 & 35.259 & & 41.870 & 36.687 \\
\hline 1625 & 33.939 & & 43.174 & 36.224 \\
\hline 1626 & & & 49.716 & 29.603 \\
\hline 1627 & & & 69.824 & 56.992 \\
\hline 1628 & & & 61.463 & 51.781 \\
\hline 1629 & & & 59.962 & 31.814 \\
\hline 1630 & & & 75.412 & 55.695 \\
\hline 1631 & & & 60.121 & 69.163 \\
\hline 1632 & & & 67.367 & 61.278 \\
\hline 1633 & & & 40.260 & 43.638 \\
\hline 1634 & & & 51.195 & 48.899 \\
\hline 1635 & & & 42.397 & 37.672 \\
\hline
\end{tabular}

111. AHPLR, Beneficencia, 35.

112. AHPLR, Beneficencia, 35, se calculan contemplando el precio de venta del grano en cada año. 
Debido al deficiente sistema de registro y delimitación de las propiedades se encuentran numerosas peticiones de apeo y amojonamiento, tanto por sospechas de apropiamiento o mala gestión del terreno como por petición de administradores y visitadores para la correcta relación de la documentación, especialmente cuando las posesiones se encuentran desperdigadas por diferentes poblaciones, para lo cual se recurre a la Justicia de la administración local, nombrándose agrimensores por parte del solicitante y de la localidad con el fin de prevenir conflictos. En 1628 se realiza en Grañón el apeo de las propiedades del hospital, dado que "esttan muchas heredades perdidas sin saber adonde ni donde son [..] en los terminos de esta $v^{a} y$ otras partes por estar defraudados y menoscabados"113, en total se refieren 128 propiedades de diverso tamaño, entre 2-3 celemines y algunas de tres o cuatro fanegas, para un total de 198,5 fanegas. Entre ellas destaca una de siete fanegas donación de "Juan de Samano, marqués", posiblemente se trate de uno de los señores de Villabenázar, villa en la jurisdicción de Grañón. Aunque el marquesado de Villabenázar no fue confirmado hasta 1666 por Carlos II, el mayorazgo fundado en 1537 por Juan de Sámano I Señor de Villabenázar llevaba vinculado el título de marqués ${ }^{114}$, se trata probablemente del dicho Juan de Sámano, fallecido en 1558 a juzgar por los pleitos sobre su testamento por parte de sus hijos ${ }^{115}$. En 1699 el Hospital de Herramélluri presenta una relación de haberes por petición de Gregorio de la Puente, administrador de "los Vienes Puros y Rentas" del Hospital del Refugio de Nájera, el agrimensor ofrece un total de 28.951 varas, correspondiente con 32 fanegas, 10 celemines, medio cuartillo y 13 varas $^{116}$.

En 1694 se realiza una relación de bienes del Hospital de Peregrinos por petición del Provisor en los términos de Cuzcurrita, Tirgo y Ochánduri, resultando un total de 65 heredades de diversos tamaños para un total de más de doscientas mil varas ${ }^{117}$. Las propiedades dependientes del cabildo de Santo Domingo están dispersas por decenas de poblaciones, por lo que es habitual encontrarse conflictos judiciales con el Hospital por toda la región, el apeo completo en 1709 ofrece un total de 190 heredades que suman 718 fanegas, a mediados del siglo XVIII, el auto de visita del Obispo Diego de Rojas muestra que 200 de ellas están en término de Santo Domingo ${ }^{118}$.

113. AHPLR, Judicial, 1246/2, 1628, Grañón, escribanía de Francisco de Porres.

114. Concedido a raíz de sus múltiples servicios: Comendador de la Orden de Santiago, Prestamero Mayor de Vizcaya, Secretario del Consejo de Indias (AGI, Indiferente, 420/8), ostentó el monopolio de las escribanías mayores del Gobierno y Audiencias y Chancillerías de Indias (AGI, Indiferente, 419/5).

115. ARChV, 1285/46, 02/03/1574, escribanía de Fernando Alonso.

116. AHPLR, Judicial, 682/4, 1699, escribanía de Juan del Valle. Valle.

117. AHPLR, Judicial, 713/3, 1694, Santo Domingo de La Calzada, escribanía de Juan del

118. SÁENZ TERREROS, $M^{a} V^{a}$, El hospital..., p. 71. 
El Hospital de la Abadía cuenta en 1607, un año en el que se procuró sanear las cuentas del hospital, únicamente por razón de sus rentas con 16.000 mrs. en dinero y 139 ff. de trigo y 75 de cebada en grano "fuera de las tierras que estan bacas" $^{\prime 119}$. A principios del siglo XVII se muestra un esfuerzo por normalizar el cobro de censos y donaciones tras el efecto de la peste de 1599, que supuso el traspaso y nueva adjudicación de estas deudas, mientras que en 1598 se encuentran pagos en grano por 88 censos y 21 en dinero y especies, ya en 1601 ha subido a 95 en grano y 23 en especie. Aún considerando los impagos, los censos aplicados se sitúan entre unos pocos celemines y la media docena de fanegas de grano, en su mayoría una fanega de trigo. Las circunstancias del siglo XVII pueden comprobarse en el Libro de Rentas de $1685^{120}$, pese a la afirmación en la portada "Este Libro es inutil por simple y por no ser mas que anotaciones de los Pueblos donde ay rentas y lo que de ellas iba cobrando el Administrador que exercia el Año de 1685", puede constatarse un aumento del tamaño de las propiedades, encontrando un mayor número de censos que superan la fanega e incluso alcanzando las 6 ó 7, por lo que los beneficios potenciales se mantendrían pese a que los censos pagaderos por grano se han reducido a 55 heredades. Los censos pagaderos en dinero y especies suman 43, entre los que puede hallarse una mayor variedad de razones, como préstamos, mandas testamentarias y arrendamientos propiamente señalados como tales. Entre los años 1622 y 1643 el Hospital de la Abadía cuenta con unas rentas en dinero potenciales de 31.344 mrs., con excepción del año 1622 en el que registra 50.011 mrs. por ajustes de cuentas atrasadas y 1643 con 22.724 mrs. En cuanto al grano los censos preveen entre $134 \mathrm{ff}$. y 8 celemines y $140 \mathrm{ff}$. y 8 c. de trigo y 65 ff. y medio celemín de cebada ${ }^{121}$, suficientes para obtener ganancias con respecto a los gastos totales del hospital, de los que alrededor de un 50\% se emplean en la asistencia a los enfermos incluso en los años con gastos imprevistos, que no alcanzan los casi 100.000 a 150.000 maravedíes a que equivalen los ingresos regulares en función a la cotización del grano a los que habría que sumar las limosnas y donaciones otorgadas al hospital. El total de la suma de las rentas en estos años ofrecido en el libro de cuentas hace un total de 24.355 reales, $2.980 \mathrm{ff}$. y 6 c. de trigo y $1.430 \mathrm{ff}$. y $11 \mathrm{c}$. de cebada, equivalente con el precio de 12 rs./f. de trigo y 6 rs./f. de cebada, el más bajo que se ofrece para este periodo, a 2.335.630 mrs., 106.165 mrs. anuales, convirtiendo el Hospital de la Abadía en una institución con superávit que no

119. AHPLR, DP 227/2, f. 1, este libro refiere como origen del contrato ligado a la deuda, al Libro Viejo o el Libro Nuevo de contratos, el Libro Nuevo se corresponde con el Libro de escrituras de censo y ratificaciones (1572-1595) (AHPLR, DP 224/2), como puede comprobarse al cruzar diferentes entradas.

120. AHPLR, DP 227/3, se extiende el registro de pagos hasta el año 1699.

121. AHPLR, DP, 225/1, Libro de toma de cuenta y razón de la administración de los años 1622 a 1643 (1643-1644). Traslado (1645). 
parece aumentar sus labores asistenciales, por lo que no es de extrañar que el Hospital del Refugio termine por desbancarlo como hospital de la villa.

Cercano temporalmente, el ajuste de cuentas del Hospital de Rocamador de Logroño para los años 1650-1656 cuenta un total de 133 censos de diferentes tipos y cuantías, pero este hospital no cuenta con tantas propiedades como los de otras localidades, obteniendo casi 100 fanegas anuales de 21 censos, 35 de ellos son préstamos con fondos del hospital, y los restantes son censos perpetuos sobre propiedades y Obras Pías. El sumatorio del cargo de estos años ofrece 3.084.669 mrs. y 285,5 ff. de trigo, el del descargo 3.179.952,5 mrs., todo el trigo es gastado en pan y el pago a la panadera, quedándose a deber al administrador 95.283,5 mrs., pero como se comentó anteriormente restaban por pagar de los Juros sobre las merindades de la Ciudad del año 1656 un total de 96.656 mrs., lo cual arrojaría un superávit de 1.373 maravedíes más lo obtenido o ahorrado por el grano, aún contándose con que la mitad de los préstamos concedidos siguen en activo.

De estas cuentas, teniendo en cuenta los procesos de devaluación de la moneda sufridos en el siglo XVII, puede observase el crecimiento tanto en tamaño como de los hospitales riojanos, en especial en los núcleos urbanos, donde tienen que hacerse cargo de las masas de jornaleros que acuden a las ciudades en busca de trabajo o de mayores posibilidades de recibir caridad, pese a los intentos de las diferentes localidades en mantenerlos para asegurarse la mano de obra necesaria para las cosechas. Un sistema previamente ocupado por las instituciones religiosas se diversifica con la adición de las cofradías y el mayor interés de los municipios en la existencia de estructuras benéficosanitarias que permiten la reducción del problema del pauperismo aún con escaso resultado y se hacen necesarias para responder ante los periodos de crisis. Son un activo que no sólo pone a disposición de sus administradores unos recursos económicos que en las ciudades como mínimo se han triplicado, de acuerdo con las concepciones sanitarias en cuanto a las teorías etiológicas de la enfermedad, el aislamiento y la cuarentena son las actuaciones fundamentales frente a las grandes epidemias como la peste de 1599, durante la cual se observa el alcance de las supuestas justificaciones caritativas como única motivación de la Beneficencia con respecto a los hospitales con función sanitaria. Ante la necesidad de espacios en los que aislar a los enfermos, los pobres, fundamentales ocupantes de los hospitales, serán expulsados de ellos para hacer sitio para los vecinos infectados y trasladados a otras instituciones benéficas, no contemplando la integración de los diferentes estratos sociales ni siquiera en estas situaciones, lo cual refuerza la idea de que la idea que más calado tiene dentro de los conceptos humanistas no es la ayuda al necesitado, sino los posibles beneficios obtenidos mediante estas acciones. 